University of Louisville

ThinkIR: The University of Louisville's Institutional Repository

Electronic Theses and Dissertations

$12-2019$

\title{
Reaching zero waste: determining the student perspective on campus food waste.
}

Cassie Anne Parkins

Follow this and additional works at: https://ir.library.louisville.edu/etd

Part of the Agricultural and Resource Economics Commons, Food Studies Commons, and the Higher Education Commons

\section{Recommended Citation}

Parkins, Cassie Anne, "Reaching zero waste: determining the student perspective on campus food waste." (2019). Electronic Theses and Dissertations. Paper 3398.

https://doi.org/10.18297/etd/3398

This Master's Thesis is brought to you for free and open access by ThinkIR: The University of Louisville's Institutional Repository. It has been accepted for inclusion in Electronic Theses and Dissertations by an authorized administrator of ThinkIR: The University of Louisville's Institutional Repository. This title appears here courtesy of the author, who has retained all other copyrights. For more information, please contact thinkir@louisville.edu. 


\title{
REACHING ZERO WASTE:
}

DETERMINING THE STUDENT PERSPECTIVE ON CAMPUS FOOD WASTE

\section{By}

Cassie Anne Parkins

B.S., Christopher Newport University, 2017

\author{
A Thesis \\ Submitted to the Faculty of the \\ Graduate School of the University of Louisville \\ in Partial Fulfillment of the Requirements \\ for the Degree of \\ Master of Science \\ in Interdisciplinary Studies: Sustainability
Interdisciplinary Studies
University of Louisville
Louisville, Kentucky

December 2019 
Copyright 2019 by Cassie Anne Parkins

All rights reserved 

REACHING ZERO WASTE:

DETERMINING THE STUDENT PERSPECTIVE ON CAMPUS FOOD WASTE

$$
\text { By }
$$

Cassie Anne Parkins

B.S., Christopher Newport University, 2017

A Thesis Approved on

September 20, 2019

by the following Thesis Committee:

Dr. Lisa Markowitz

Dr. Angela Storey

Dr. Daniel DeCaro 


\section{DEDICATION}

This thesis is dedicated to my parents

Mr. Steve Parkins

and

Mrs. Lorna Parkins

who give unwavering encouragement

and support in my endeavors 


\section{ACKNOWLEDGMENTS}

I would like to thank my advisor, Dr. Lisa Markowitz, for her guidance and encouragement to help me navigate this research. I would also like to thank the other members of my committee, Dr. Angela Storey, and Dr. Daniel DeCaro, in their feedback pointing me in the right direction. I want to thank Ellen Trahan for being a source of ideas and understanding as I pursued this research. I am also grateful for the constant support, even from a distance, from my parents, Steve and Lorna Parkins, and my siblings, Shelby, Lucas, and Davis. 


\section{ABSTRACT \\ REACHING ZERO WASTE: DETERMINING THE STUDENT PERSPECTIVE ON CAMPUS FOOD WASTE \\ Cassie Parkins}

September 20, 2019

Food waste is an ongoing problem in the complex global food system. College campuses are in a unique position to address food waste through reducing it in their own food systems and by encouraging students to develop behaviors to reduce and divert waste from landfills. In this thesis project I seek to understand how students consider food waste and their attitudes and ideas about reducing it. To this end, I observed student behaviors and waste in University of Louisville's all-you-care-to-eat dining hall and weighed plate waste there. I conducted informational interviews with University and Aramark employees, along with semi-structured interviews with students. These findings point to ways that messages connecting healthfulness and personal cost to food waste could potentially reach more students harboring underlying beliefs about the adverse environmental and social impacts of food waste. Moreover, the University could be much more vigilant in promoting and coordinating waste reduction efforts. 


\section{TABLE OF CONTENTS}

PAGE

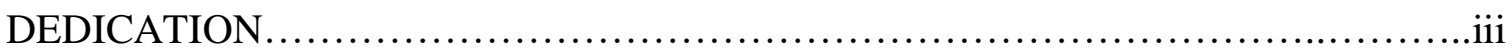

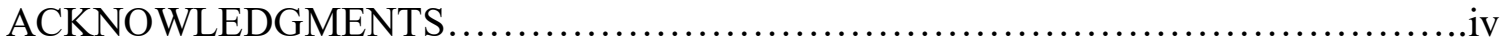

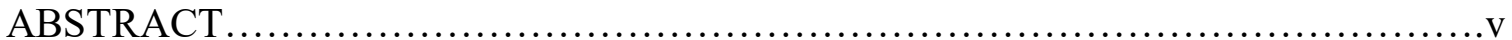

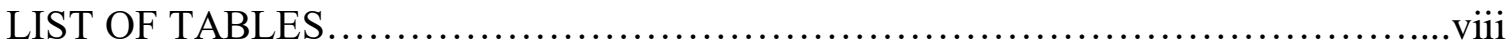

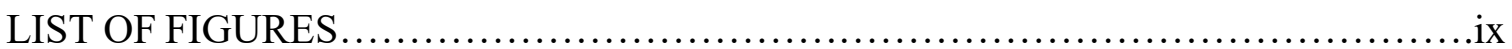

CHAPTER 1: INTRODUCTION, LITERATURE REVIEW, \& METHODS ...............

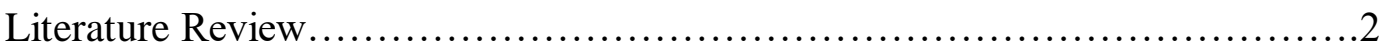

Methods................................................................. 17

CHAPTER 2: U OF L FOOD SYSTEM AND THE VILLE GRILL .....................22

University of Louisville Food System.................................23

The Ville Grill............................................................... 32

CHAPTER 3: WHAT DO STUDENTS HAVE TO SAY ABOUT FOOD WASTE?........42

Coding and Collating Responses.......................................43

The Sample: Demographic Characteristics.................................44

Dining Hall Preferences..............................................47

Awareness of Waste Management.........................................49

What Generates Food Waste..............................................50

Attitudes toward Food Waste................................................52

How to Reduce Food Waste...........................................57

Conclusion..........................................................60

CHAPTER 4: DICUSSION, RECOMMENDATIONS, \& CONCLUSION..............62 
Interview Discussion.

U of L Food System Revisited..........................................65

Research Limitations............................................. 70

Future Research Recommendations.....................................72

Conclusion...................................................... 74

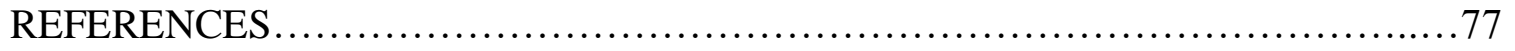

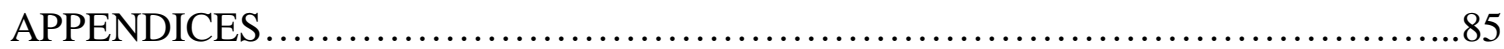

CURRICULUM VITA..................................................... 93 


\section{LIST OF TABLES}

TABLE

PAGE

1. Gender from Weigh the Waste............................................ 35

2. Food Waste Weighing Data.................................................... 39

3. Question 1 Responses...............................................48

4. Question 3 Responses..................................................... 52

5. Reasons for Question 4 Response ........................................ 54 


\section{LIST OF FIGURES}

FIGURE

PAGE

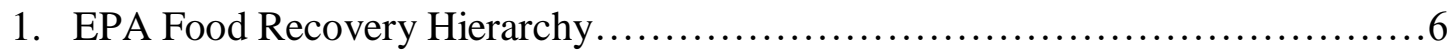

2. Gender Distribution..................................................45

3. Year in School......................................................45

4. Age Distribution...................................................46

5. Major Distribution................................................. 46

6. Hometown Distribution...............................................46

7. a) Responses for food waste in the Ville Grill. b) Responses for food waste elsewhere on campus.............................................50

8. Question 4 Responses...............................................53

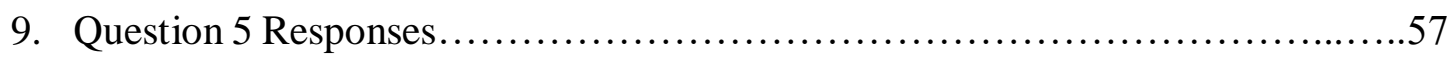

10. Question 6 Responses............................................... 58

11. Question 7 Responses.............................................60

A1. Meal Plan Website..................................................... 86

A2. Traditional Plan Information........................................... 87

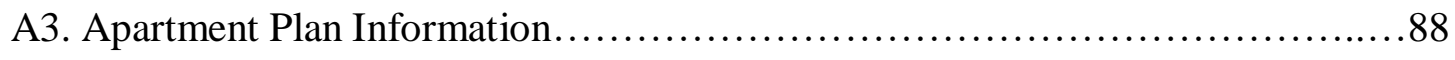

A4. Commuter Plan Information.......................................... 89

A5. Campus Map for Dining and Residence Hall Proximity ........................90

A6. Former Sign about Tasting Dishes ................................... 91

A7. New Taste Don't Waste Sign........................................ 91 
A8. Ville Grill Compost Signs......

A9. Clean Plate Award Sticker............................................. 92

A10. Weigh the Waste Images......................................... 92 


\section{CHAPTER 1:}

\section{INTRODUCTION, LITERATURE REVIEW, \& METHODS}

Food waste-does confronting people about it shame them so much it might lead to obesity? One woman suggested this after I asked her to dump her food waste into a clear bin in front of me as I collected plates of waste from people in the all-you-can-eat dining hall at University of Louisville. Perhaps she, like many others, was made uncomfortable by the spotlight put on waste as we weighed it in front of everyone. Eliciting that awkward feeling, or any emotion at all, is partly the purpose of showing people their waste because it may prompt thought about what happens to it or how they are contributing, even if only for the few seconds it takes to push the food off their plates.

Weighing waste in a dining hall at the University of Louisville was the start to exploring food waste on a college campus where sustainability is purported to be a priority. Sustainability, in essence, pertains to harmonizing the three facets of environment, social equity, and economic prosperity to improve the world we live in for present and future generations (Weisser, 2017). One societal issue requiring a sustainable solution is waste, as its existence and traditional management methods tend to contribute to environmental and social equity problems (Conrad et al., 2018; Breewood, 2019). Reducing food waste is a challenging hurdle to reach zero waste as many cultural and emotional ties to food influence how people may or may not consider food waste. I selected University of Louisville's all-you-can-eat dining hall as the focus of my study 
for several reasons, including the location's emphasis on encouraging diners to reduce their waste. My main research question is why are students wasting food in an environment that encourages waste reduction? To answer this question, I not only interviewed students to elicit their perspectives, but also examined the campus food system and its potential influences on student behavior. The objectives of this research are to: 1) characterize food waste in the University of Louisville's food system, 2) determine student attitudes and perceptions regarding their own role in campus food loss and waste, and 3) translate the student perspective into useful suggestions for campus food system planners so that new programs can more easily accommodate students' attitudes and perspectives.

To form the backdrop to my research, I reviewed literature on food waste, specifically defining this term and its environmental and social consequences. I also discuss consumers and the retail food industry before delving into food waste on college campuses and the role of students. Following the literature review is an overview of the methods employed in my research.

\section{Literature Review}

Defining food loss and waste is challenging because the inclusion of certain foods or food products varies - such as inedible parts of food or edible food produced for purposes other than human consumption — as explained by Helen Breewood (2019) in a description of numerous uses and delineations of food loss and waste. Commonly applied definitions of food loss and waste from the FAO (similar to those from the World Resources Institute) use food loss to refer to any damage resulting in a reduction of human-edible food along the food chain before reaching consumers (i.e. in production or 
processing), while food waste occurs only at the retail and consumer levels. These definitions exclude inedible parts of food and food produced for animal feed. Differing notions of edibility add ambiguity in defining food loss or waste as some people may consider animal fat or chicken feet inedible while others may not. Compounding the uncertainties around worldwide food waste figures, and the association of waste with scarcity, is the exclusion from the waste count of food produced for animals since the amount of land used to produce animal feed accounts for about 40 percent of arable land. That said, in this thesis, I use a set of definitions from the FAO: food loss refers to food not consumed for any reason and at any point along the food chain, and food waste is a subset of loss where edible food is discarded for preventable reasons. (Breewood, 2019).

\section{Consequences of Food Waste}

Food loss and waste occur globally and are linked to severe environmental and social consequences. About one-third of food produced globally is lost or wastedamounting to around 1.3 billion tons annually (Pinto et al., 2018; Breewood, 2019). In the United States, consumers contribute significantly to food loss: 22 percent of the food available for consumption is lost at the consumer level, and over 60 percent of this food loss is considered preventable (Mekonnen \& Fulton, 2018; Nikolaus, NickolsRichardson, \& Ellison, 2018). Compared to other regions in the world, North America ranks among the highest in consumer-stage food waste per capita (Breewood, 2019). Wealthy nations tend to generate more food waste because of large stocks of food present for retail to provide consumers options (Breewood, 2019). Further, people can typically better afford food waste than those in lower income countries since food costs make up a relatively small portion of their expenses (Breewood, 2019). Food loss in developing 
countries can occur from unsanitary conditions in markets and insufficient processing facilities, while food waste more often comes from poor storage conditions, leading to food spoilage (Breewood, 2019).

In the United States, food waste is associated with various adverse environmental impacts, including the allocation of millions of acres of cropland, trillions of gallons of water, and massive amounts of pesticides (which are manufactured using fossil fuels) to produce food that will ultimately go to waste (Conrad et al., 2018). Consumers reported wasting fruits and vegetables more than any other food group, which largely contributes to the amount of cropland and water going to waste in production since fruits and vegetables require higher inputs per acre of land compared to other food groups (Conrad et al., 2018). Mekonnen and Fulton (2018) calculate environmental impacts of various diets and food waste by examining each food group's water footprint, which is a measurement of the direct and indirect use of water in producing a good or service. Red meat has the largest water footprint for wasted food at both the retail and consumer levels, although it has a much higher percentage out of all food groups at the consumer level (Mekonnen \& Fulton, 2018). Mekonnen and Fulton (2018) consider reducing the amount of dairy or meat in a person's diet as a way to conserve water, but they argue that reducing food waste will be the most impactful in shrinking one's water footprint.

Food waste management can harm or enrich the physical environment, depending on the method. The widespread practice of landfilling significantly contributes to climate change by generating massive amounts of greenhouse gases (Tonini, Albizzati, \& Astrup, 2018). Anaerobic digestion is a process for decomposing organic matter in oxygen-free containment where the methane gas produced is more easily controlled than by 
landfilling (Lin et al., 2018). The methane from anaerobic digestion is used as a biogas to substitute fossil fuels, and the processed matter can be added to soil (Lin et al., 2018).

An alternative method for waste management, composting, helps offset environmental problems from fossil fuels by replacing synthetic fertilizers (Tonini et al., 2018). Composting also diverts food and organic waste form landfills so that these materials do not add to greenhouse gas emissions (Mu et al., 2016). Instead, food and other organic matter (such as paper products) decompose and become a soil additive similar to fertilizer because the processed compost contains important nutrients like nitrogen (Mu et al., 2016; Lin et al., 2018). Even though composting food waste provides several benefits and can be managed on a smaller scale than anaerobic digestion, communities and companies tend to oppose it for several reasons (Mu et al., 2016). People often object to the smell coming from decomposition when the process is in open air, and it is not always profitable for companies, whether due to unpredictable environmental factors like weather or an inability to sell the final product ( $\mathrm{Mu}$ et al., 2016). Despite the resolvable challenges, composting provides more benefits than harm to the natural environment, and it is therefore implemented as a tactic to divert food waste from landfills.

State agencies, concerned with preventing or at least mitigating food waste, have developed useful rubrics establishing hierarchies for food loss and waste. The U.S. Environmental Protection Agency (EPA) and the United Kingdom's Waste and Resources Action Program (WRAP) employ similar hierarchies to prioritize waste reduction and diversion efforts (EPA's graphic shown in Figure 1) ("Sustainable Management," 2017; Breewood, 2019). The highest priority is to prevent waste and, as 
the EPA specifies, reduce the amount of surplus food produced. The second highest priority is to direct any salvageable food to people in need, and the third level is to arrange for food that cannot be given to people to become animal feed. WRAP's hierarchy has recycling as the next priority, which includes anaerobic digestion or composting, whereas the EPA only mentions composting. The last resort for waste that cannot be used for any of the above purposes is to send it to landfill or incinerate (with no energy recovery). (“Sustainable Management,” 2017; Breewood, 2019).

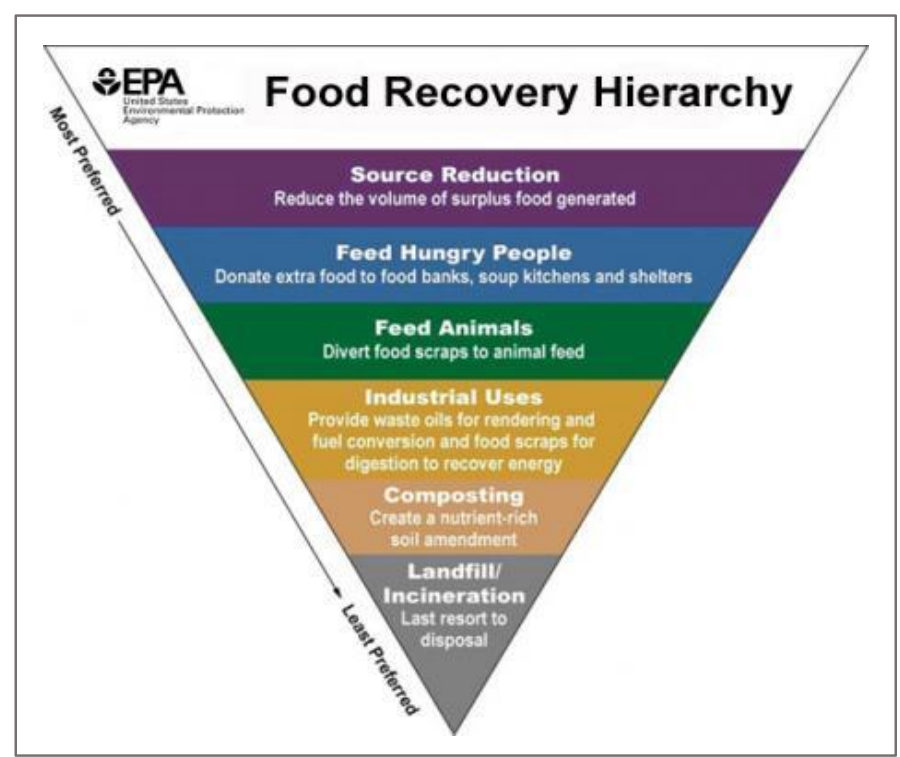

Figure 1. EPA Food Recovery Hierarchy. ("Sustainable Management," 2017).

Food waste is also associated with adverse social impacts because it is occurring within the same country (the United States) where about twelve percent of households suffer food insecurity (Ahmed et al., 2018). It is unclear how food waste directly impacts the persistence of hunger and food insecurity, although connecting these two issues as happening concurrently is prevalent (Ahmed et al., 2018; Benson, Daniell, \& Otten, 2018; Breewood, 2019; Martin-Rios et al., 2018; Barrett, 2014). Food waste is measured by calories to help demonstrate the paradox of uneaten food coexisting with malnourished people. According to the World Resources Institute, 24 percent of the food 
calories globally produced for human consumption are lost or wasted each year (Breewood, 2019). Benson et al. (2018) estimate that reducing the amount of wasted food by 15 percent "could feed 25 million Americans," however the authors do not explain how this would happen (p. 554).

Current food production is enough to feed the entire global population when assessing total food mass and caloric needs (Caprita, 2016). Improving production in ways to eliminate food loss could lead to feeding more people, such as farmers having enough to feed themselves (Caprita, 2016). In developed countries, one method to prevent food from going to waste is by donating it to food banks, which helps food insecure people (Caprita, 2016). Unfortunately, not all food on track to become waste can be donated in light of concerns and legalities around food safety (Lohnes \& Wilson, 2018). It remains unclear how reducing food waste fixes food insecurity in countries such as the United States, even with the short-term solution of food donation. Households produce the most food waste in developed countries, accounting for 40 percent of the total (Caprita, 2016). The United Nations' sustainability goals suggest that the objective is to eradicate hunger and food insecurity, but Caprita (2016) does not elaborate on how reducing household waste would improve food access (nor it is mentioned in Ahmed et al., 2018; Benson et al., 2018; Breewood, 2019; Martin-Rios et al., 2018; Barrett, 2014). Consumers, Food Industry, and Sustainability

An individual's decision making on what and how to eat can help inform behaviors around food waste because considering (or disregarding) the possibility of waste is tied with priorities around food. Choosing what to eat is conceptualized by food historian Warren Belasco (2008) as a triangle connecting three factors-identity, 
convenience, and responsibility. Belasco argues that most people base their decisions on identity and convenience over responsibility. Identity refers to personal preferences influenced by cultural matters such as familial or ethnic background, values, and other factors like taste. Convenience pertains to price, ease of access or preparation, cooking ability and other variables that influence a person's ability to attain food. The third factor, responsibility, is often the lowest priority in consideration, but Belasco argues that it may be the most important. Responsibility encompasses awareness of the personal, social, and environmental consequences of one's decision. The risk of wasting food in deciding what to eat, or how much to take, falls into the category of responsibility.

Hannibal and Vedlitz (2018) conducted a study to determine citizens' perspectives on food waste in the food retail industry. They concluded that individuals are moderately concerned about food waste from food service organizations; however, the level of support for policy-related solutions such as building compost facilities varied depending on factors including gender or political ideology. A low level of awareness regarding the connections between food waste and resource use resulted in a lack of support for solutions to reduce waste. In studying efforts of public agencies to aid in reducing food waste, Benson et al. (2018) find that one of the challenges to successful prevention and reduction efforts is misperceptions and different priorities among stakeholders. The same challenges are likely present in the complex landscape of food waste on college campuses.

Companies in the food industry work to reduce their food waste, even if only to save money (Martin-Rios et al., 2018). The Vice President for Sustainable Development for the food service firm, Sodexo, emphasizes open communication and collaboration 
between companies along the "value-chain" for the food industry, along with education campaigns to teach employees and consumers about reducing food waste (Barrett, 2014). Long, Looijen, and Block (2017) studied the factors that helped in transitioning to more sustainable business models in the food industry in the Netherlands. They found that collaboration among companies within the supply chain to be the most valuable, along with continual improvement of the new initiatives, and fostering company culture around a clear vision related to sustainability. Food service contractors Aramark, Sodexo, and Bon-Apétite work toward sustainability by composting, donating leftover food when possible, and supporting local and organic sources (Sullivan, 2012).

\section{College Campus Food Waste}

With the mission of education, colleges and universities hold a unique position in being able to help solve sustainability problems, including food waste (Uhl \& Anderson, 2001). The complexity of social and environmental challenges calls for education of young people and those involved in research and teaching to incorporate sustainability into their priorities (Uhl \& Anderson, 2001). Colleges can provide space and resources devoted to analyzing the operation of the conventional food system, while also exploring and testing alternative processes (Barlett, 2011). Young adults (ages 18 to 24, including typical college-age adults) are perceived to produce high levels of food waste because this age group often has a large focus on convenience, limited experience managing food, and a fast-paced culture that may conflict with waste reduction efforts (Nikolaus et al., 2018). Not only do universities have the responsibility to educate and find solutions to complex problems, but the largest portion of their population is heavily contributing to 
the amount of waste generated in the United States, positioning universities as the ideal location to find successful methods to reduce food waste.

As the experience of Ohio State University revealed (Wright, 2012), to cut waste successfully a school needs stakeholder involvement, education, and infrastructure in order to bolster a protocol reducing waste and diverting any unavoidable waste from landfills. Ohio State University aims to generate zero waste at events, and in 2012, they were able to divert 98 percent of their waste away from landfilling during a football game (“Zero Waste," n.d.; Wright, 2012). To achieve this, Ohio State made all disposable material compostable or recyclable and bought recycle and compost collection bins. Perhaps the most crucial component in reaching zero waste is working with a local nonprofit to bring in young people who help monitor the bins and inform people how to sort their waste (“Zero Waste at Ohio," 2019).

Collaboration among stakeholders is essential in working toward zero waste because it can foster opportunities for progress both within a university and the surrounding community. Ohio State and a nearby mulch and compost company, called Price Farms Organics, worked together to find a way for the university to send organic matter to Price Farms, benefitting both parties (Wright, 2012). As previously mentioned, Ohio State also partners with a local non-profit organization teaching high school and college students life skills to provide the university with volunteers who monitor compost and recycle bins (“Zero Waste at Ohio,” 2019; “Our Programs,” 2019). Students are another important stakeholder, as they may start up a composting program on campus or add their university as a chapter in the Food Recovery Network (Siegrist, 2015; Tucker, 2013). Whether or not they begin composting on campus, students are often involved in 
picking up the collection from residence halls and processing compost on site (Siegrist, 2015; Mu et al., 2016). Student leaders in the Food Recovery Network work with the dining locations on campus to arrange picking up leftover food and delivering it to local food pantries (Tucker, 2013). To achieve zero waste, universities must work with local organizations to better manage their food waste and encourage student engagement with on-campus initiatives.

Education is a key component in cultivating successful programs for reducing waste. At Ohio State football games, student volunteers serve to educate people about what is compostable or recyclable as they monitor these bins ("Zero Waste at Ohio," 2019). Several studies focus on the effectiveness of advertising and education encouraging students to waste less food in dining halls (Pinto et al., 2018; Whitehair et al., 2013; Ahmed et al., 2018). In the study from Whitehair et al. (2013), students responded better to a simple sign reminding them to not waste food. In another study (Pinto et al., 2018), signs called on students to reduce waste by cleaning their plates and made them aware that the food they do not eat goes to garbage. Programs, interns, and volunteers help teach students about what can and cannot be composted to help their campus compost system succeed (Siegrist, 2015). Without frequent reminders and education, initiatives to reach zero waste on campus cannot flourish since they require participation from everyone.

In conjunction with education, infrastructure is a necessity as it can help encourage desired behaviors. In addition to collection bins for compost and recycling, informational signage posted by the bins is crucial in case people are uncertain of how to sort their waste (Wright, 2012). Exemplified by Ohio State, reliance on compostable and 
recyclable materials for food packaging goes beyond reducing food waste to cut overall waste (Wright, 2012).

Universities with zero waste goals should institute strategies to divert any waste that cannot be reduced away from landfills. Ohio State mainly focuses on recycling and composting at their events to divert waste (Wright, 2012). The Food Recovery Network focuses on food donations; although there are challenges around donations with food safety such as student volunteers potentially not washing their hands before handling food (Schonberger et al., 2018). Composting can vary widely on different campuses because of factors such as space and investment ability. An example of a nearly closedloop system on Kean University campus in New Jersey involves an in-vessel compost processor, which helps the materials break down and become soil faster than open-air systems (Mu et al., 2016). Once the compost becomes a soil additive, it is used in a campus community garden growing vegetables for use in a nearby dining hall. An invessel composter requires high up-front costs, and some schools would not need it because they have more space for some form of open-air composting (Mu et al., 2016; Siegrist, 2015).

\section{Role of Students in Reducing Food Waste}

The students' role in a college's efforts to reduce food waste is crucial as a main actor in the food system. Many studies examine student behavior and how to encourage students to reduce waste (Whitehair et al., 2013; Nikolaus et al., 2018; Zhang et al., 2017; Marais et al., 2017; Pinto et al., 2018; Sarjahani et al., 2009; Campbell-Arvai, 2015). I broke down this body of work by the authors' emphases on, in turn, student behaviors, their attitudes and beliefs, and their perceptions and awareness. 
Behavior. Whitehair et al. (2013) conducted surveys and waste weighing in a dining hall to determine the effect of written messages reminding students to not waste food, in addition to asking students about their beliefs related to food waste and sustainability. Two different types of messages were tested, one of which displays statistics about food waste and how much waste the dining hall produces, and then a simpler message that states "eat what you take, don't waste food." The simpler message elicited a significant decrease in the food waste left on students' plates, whereas the longer message did not prompt a similar reduction in waste. Through the surveys, the study also found that students generally agree food waste has negative consequences and should be reduced; however, these beliefs did not seem to influence waste-reducing behaviors as students held the beliefs before they saw the different messages leading to a decrease in food waste.

Nikolaus et al. (2018) studied the influence of living situations on food waste behavior in young adults and held discussions to better understand the students' perspectives. Noticeable differences were found between people living on campus and off campus, mainly because the latter bought and prepared food (or lived with their parents who did this). From the discussion, the researchers developed a list of factors influencing food waste behaviors either positively or negatively, depending on the situation, including portion sizes, personal values, connection (or disconnection) with cost, and connection (or disconnection) with the preparer. They found that sharing food with others reduces food waste and can be facilitated by living on campus because of the close quarters and frequent interactions with fellow students. On the other hand, prioritizing 
convenience appeared to increase food waste because, for example, students may take larger portions on their plate to avoid waiting in line multiple times.

A study in Beijing, from Zhang et al. (2017), analyzed the behaviors of college students in respect to sorting their waste - a practice becoming more common in urban areas in China to reduce waste and increase recycling. In the study, food waste is one of the three categories to separate out from mixed waste, in addition to recyclables and hazardous waste. The results show almost half of participating students sort none of their waste, and among those who do sort, food waste is the least commonly separated.

Interestingly, students did display high levels of accuracy in classifying waste into their proper categories. The three most common reasons students do not sort their waste relate to convenience, including no place for different bins, no access to separation facilities, and "separation is too troublesome," (p. 448). These studies demonstrate how convenience can impact food waste behavior, while knowledge or beliefs favoring food waste reduction do not necessarily affect a student's actions (Nikolaus et al., 2018; Zhang et al., 2017; Whitehair et al., 2013).

Attitudes and beliefs. Attitudes toward food waste refer to one's concern or belief about the consequences of waste and whether or not people should waste food. There is little empirical evidence linking positive attitudes to positive behaviors (i.e. believing waste is bad does not necessarily lead to strong efforts to reduce waste) (Zhang et al., 2017), which is confirmed in the study by Whitehair et al. (2013). Zhang et al. (2017) highlight a decline in agreement with statements when the phrase "I feel guilty" or the suggestion of making extra effort to separate waste is included. This change in attitude indicates a lack of personal connection and responsibility toward environmental issues, implying people 
may not believe that their individual effort can make a difference (also mentioned in Nikolaus et al., 2018).

Ahmed et al. (2018) study how to reduce food waste on a college campus by surveying students to understand their attitudes toward waste. They found that most students are concerned about the amount of food waste created in the United States, although they do not necessarily think about food waste on a regular basis. The study also concluded that students may be more concerned with food waste if they were more aware of the costs associated with it.

Investigators at Stellenbosch University in South Africa examined the attitudes and beliefs of students as well as those of food service managers and catering personnel by conducting in-person interview and surveys (Marais et al., 2017). All three groups generally agreed that reducing food waste is important. Students and catering personnel shared the view that they can personally do more to reduce food waste, whereas food service managers expressed mixed attitudes toward this statement. In contrast to Zhang et al. (2017) and Nikolaus et al. (2018), Marais et al. (2017) find individual concern and desire for action from students (and catering staff) regarding food waste. Perceptions and awareness. In examining awareness and knowledge of food waste issues, Nikolaus et al. (2018) argue that low levels of awareness may be related to invisibility of the consequences of waste. Campbell-Arvai (2015) studied students' views of links between environmental sustainability and food choices using surveys and focus groups. She found that students made less of a connection between reducing food waste and helping the environment than recycling and reusing materials. Students also made little mention of environmental consequences when discussing food choice in focus 
groups. Awareness and knowledge can be influenced by some of the factors that influence behavior, for example, social influence, which refers to the behaviors of friends and family (Nikolaus et al., 2018). As previously mentioned, Ahmed et al. (2018) suggest that students would be more concerned (and perhaps more inclined to reduce waste) if they knew "reducing food waste could save money on their meal plan," (p. 1088). In a quantitative study of how signs with simple messages educating students affect plate waste in a dining hall, Pinto et al. (2018) concluded that increasing awareness can lead to waste-reducing behaviors.

Many participants in the study by Nikolaus et al. (2018) perceived that general consumer waste in the United States is somewhat high, and they believed their individual waste is less than that of the average American consumer. Nikolaus et al. (2018) also point out the common perception among participants that university dining facilities were the main generators of waste. This impression led some people to defend their individual waste because they felt that dining services intentionally over-purchase food (particularly in all-you-can-eat facilities), thus reducing their guilt when wasting in this type of setting (Nikolaus et al., 2018). On the other side, Ahmed et al. (2018) discuss how dining service operators are unsure of the demand for food, which often leads to over-purchasing and wastage. While the student perspective mentioned by Nikolaus et al. (2018) is technically true, the behavior that follows seems to perpetuate the cycle of over-purchasing and waste.

I draw upon these finding and insights from previous studies in my own investigation of students' behavior and food waste at the University of Louisville. To determine students' perspectives and contextualize their behavior so new initiatives can 
more specifically target how students consider food, I pursue three objectives: 1) characterize food waste in the University of Louisville's food system, 2) uncover students' attitudes and perceptions regarding their own role in campus food loss and waste, and 3) translate the students' insights into useful suggestions for campus food system planners so that new programs can more easily accommodate students' attitudes and perspectives.

\section{Methods}

\section{Objective 1: Characterizing Food System and Waste}

To get a preliminary understanding of the food system, in addition to perusing the University’s website (“Dining Services,” 2019), I carried out informational interviews with sustainability coordinators for the University of Louisville and its food service provider, Aramark. Aramark's Sustainability Coordinator took me on a tour of the dining facilities on campus to learn about how they currently operate. To gain an appreciation of how resident students experience the food system, I conducted informational interviews with housing administrators at various levels - from a hall director to an Associate Director for Residential Life_-discussing the outreach and programming housing has related to food and food waste.

Additionally, I consulted the University website to learn how meal plansrequired for nearly all undergraduates - operate. I also met with the person who runs the composting system and a former student intern involved in zero waste activities to learn about food waste management outside of Aramark's operation. To better understand the relationship between Aramark and the University, particularly their respective roles in making campus food decisions, I met with the Executive Director of Business Services 
and the Senior Associate Vice President for Operations at U of L. I was unable to meet with more people from Aramark, aside from the Sustainability Coordinator, to learn about their perspectives as the food service provider. (See Appendix A for informational interview schedule).

The second step in characterizing food waste involves documenting the social processes where waste occurs. I focused on the all-you-can-eat dining hall-the Ville Grill—for multiple reasons. There, initiatives to reduce waste are already implemented, including the removal of trays (Sarjahani et al., 2009) and signs posted encouraging students to ask for a taste of an unfamiliar dish (Ahmed et al., 2018). The all-you-can-eat setup facilitates research since students cannot take leftover food with them when they leave the dining hall (i.e. any waste must be disposed of in the building). Moreover, previous studies on student food waste behaviors tend to address waste which occurs in all-you-can-eat style dining halls, thus affording greater comparability and ideally broader application of research findings (Ahmed et al., 2018; Whitehair et al., 2013; Nikolaus et al., 2018). Finally, the setting, designed to eliminate food waste, underscores the mystery of its persistence.

To document social processes in the Ville Grill, I observed behaviors and flows of people, including what food is being wasted and how people are disposing of it. From August 2018 through March 2019, I spent approximately 21 hours (broken into one hour lunch or dinner time shifts) observing the types of food students are wasting, in addition to the variations in how students approach the disposal area with or without food waste on their plates. I observed the ways people demonstrated variable awareness of the Ville Grill's composting (for example, by dumping their food into a trash can before returning 
their plates) along with the population of people in the dining hall. I noted the contextual factors that may affect the amount of waste or number of people eating in the Ville Grill, such as the weather outside or any large visiting group who were not students. To find out more about the population in the Ville Grill, the Sustainable Dining Intern and I took a random sample of 50 students during one waste weighing session. We asked people who were scraping food off their plates and people who returned clean plates their year in school.

Beginning in August 2018 through April 2019, I weighed plate waste in one to two-hour increments during lunch or dinner (totaling approximately 17 hours) in the Ville Grill to learn about the extent of waste and to gain a better understanding of waste patterns. My waste weighing method derives from an event regularly held in the Ville Grill called Weigh the Waste. This event involves students dumping the leftovers on their plates into a bin that sits on a scale before returning their dishes to be cleaned. As a way to better classify the waste occurring in the Ville Grill, I began taking notes on specific foods I saw while weighing. I noted the total number of people who approached the dish return as well as the number of people with food waste, and in a few sessions I took note of their apparent gender to identify qualities of the dining hall's population.

\section{Objective 2: Uncovering the Student Perspective}

Based on the previous studies on student attitudes, behaviors, beliefs, perceptions, and awareness, it is evident that each of these aspects are multi-faceted and influenced by various factors (Whitehair et al., 2013; Nikolaus et al., 2018; Zhang et al., 2017; Ahmed et al., 2018; Marais et al., 2017; Campbell-Arvai, 2015). To evaluate student attitudes, several studies utilized surveys with Likert-scale statements with which participants 
ranked their level of agreement (Marais et al., 2017; Campbell-Arvai, 2015; Whitehair et al., 2013). In studying their beliefs or values in environmental issues and sustainability or food waste in general, some researchers used Likert-scale statements in surveys (Whitehair et al., 2013; Campbell-Arvai, 2015; Marais et al., 2017). Campbell-Arvai (2015) posed open-ended questions to understand beliefs about food waste behaviors and their influence in the connections between the food system and the environment. Nikolaus et al. (2017) examined awareness and perceptions about a specific food system using open-ended questions.

I conducted 60 semi-structured interviews after receiving approval from the Institutional Review Board. I received permission from the location manager for the Ville Grill to conduct interviews therein. The interview questions are broad and applicable to the general student body as there is no data on specific demographics of the Ville Grill dining population. I created a schedule of blocks of time to spend in the dining hall interviewing students over a three week period. The blocks were arranged so that in the end I interviewed twice for each day of the week — once during lunch and once during dinner-with the exception of interviewing on Thursday three times. I implemented a systematic sampling strategy to reduce bias and ensure reasonable demographic range. Restricting my interview population to current undergraduate students, I counted the people who came to the dish return area and approached the seventh person for an interview. After a few interview sessions, I dropped to every fifth person so I did not have to wait as long in between interviews, particularly if it was not crowded. If the person approached agreed to be interviewed, I invited them to sit at a table I reserved near this area. If they did not want to be interviewed, or they were not a current 
undergraduate student, I counted to and approached the third person after them until I could conduct an interview.

Objective 3: Analyzing the Student Perspective

After all the interviews were completed, I entered the information into an Access database and typed each interview into a Word document to have an electronic copy. I coded the demographic information for each of the participants to facilitate grouping and calculating the data to describe the characteristics of the sample, including gender, age, areas of study, years in school, and where people grew up. To begin analyzing the openended responses, I reviewed all of the surveys with an iterative process of thematic coding.

The information derived from these methods are described in the following chapters. Before discussing the interview responses and analysis, I will review the characterization of University of Louisville's food system and food waste in the Ville Grill. 


\section{CHAPTER 2:}

\section{U OF L FOOD SYSTEM AND THE VILLE GRILL}

The University of Louisville demonstrates concern and attention toward sustainability through multiple initiatives across campus and new graduate and undergraduate programs focusing on this topic. The most sustainable university in Kentucky, in 2019 it received a Gold rating from the Association for the Advancement of Sustainability in Higher Education's Sustainability Tracking, Assessment and Rating System (STARS) ("University of Louisville," 2019). U of L is bicycle friendly, fosters community gardens and a free store worked and operated by student volunteers (and largely upheld by a single sustainability coordinator for campus), and follows goals for green purchasing and reducing greenhouse gas emissions, among several more programs ("U of L Sustainability,” 2019). One particular site where great strides were made to minimize food waste is in the Ville Grill dining hall. Most disposable materials in the dining hall are compostable, and it is purported that all food scraps are composted. Despite the efforts to reduce waste inside the dining hall, waste continues to be generated, and it may not all be sent to compost. Aramark - the food service provider on campusand administrators concerned with sustainability are interested in seeing the school approach zero waste, starting with diverting all food waste in the Ville Grill from landfills. 
In this chapter, I describe the food system at the University of Louisville and focus on the intricacies of the Ville Grill as a paradoxical food waste challenge and opportunity for sustainability. Through informational interviews and documentary research, I discerned the information regarding food and food waste presented to students as they acclimate to campus, as well as the administrative decisions around advertising and programs for students. From observations and waste weighing, I characterize the waste occurring in the Ville Grill and present my efforts to decipher the ways people interact with the environment and with waste.

\section{University of Louisville Food System}

Back in the 1970s, when the University of Louisville ran food services on campus, the food was dismal and there were few dining choices, according to the Executive Director in Business Services who was a student during this period (B. Knaster). He explained that the University began contracting for food services because it would vastly improve the quality of food and service, and the university could spend more time and money focusing on its main purpose-educating and distributing knowledge. U of L's transition to outsourcing followed the broader trend in the $1980 \mathrm{~s}$ and 1990s of universities in the United States privatizing food service because it greatly reduced costs (Glickman et al., 2007). In 2016, the contractor for food service changed from Sodexo to Aramark, which was a business decision based on Aramark's proposal to the school. Aramark renovated the Student Activities Center (SAC), where several food options are available, and organized the Marketplace to offer local fare in a food court setup inside the SAC (see map in Appendix C). A couple of people remarked on the improvement of campus food since Aramark took over (J. Jensen, J. Leibowitz); 
however, whether a true upgrade in quality occurred is difficult to determine since such factors as more positive interactions with servers could reduce the number of complaints (M. Watkins). One discernable aspect is the expansion of vegan and vegetarian options, and Aramark targets some of their outreach to inform people about these food options and where to find them (J. Jensen, E. Trahan); although it is difficult to satisfy everyone, as a few people suggest there are not enough vegan and vegetarian choices across campus (M. Fluharty).

Aramark strives to listen and receive feedback from students and employees (E. Trahan). There is frequent tabling in the Ville Grill and at campus events such as farmer's markets and Earth Week to provide information about meal plans, vegan and vegetarian locations, and answer any questions students may have. Aramark also conducts online surveys with students to gain specific feedback regarding their satisfaction with choices and quality in food and dining services on campus. Aramark convenes meetings with students and employees — specifically Student Government Association (SGA) members, housing staff, and employees as representatives for the university—a couple of times each semester to discuss ideas and hear input about food services on campus, such as menus and hours of operation (B. Knaster). Attendees can weigh in on any recommendations from Aramark about changes or new dining locations; however the final decision for approval (or refusal) is up to a handful of university executives (B. Knaster). For example, functional changes or repairs can be approved by the Executive Director of Business Services or the Senior Associate Vice President for Operations; whereas more significant changes (i.e. those noticeable to the campus community) require consent from these two administrators, as well as the President and the Board, 
after discussing the change with students, faculty, and staff (B. Knaster, M. Watkins). Outside of the open meetings, Mark Watkins (the Senior Associate Vice President for Operations) speaks with Aramark managers frequently and fosters a collaborative relationship between the University and the contractor (M. Watkins, E. Trahan). Sustainability

Sodexo began paving the way for initiatives including compost, removing trays from dining halls, and local food purchasing (J. Mog, "Food \& Recycling," 2011). While there were champions for sustainability working for Sodexo and the University, no fulltime employee solely focused in this area until the contract with Aramark began, and created the Sustainability Coordinator position, as required by $\mathrm{U}$ of $\mathrm{L}$ to further emphasize sustainability (J. Mog, B. Knaster, M. Watkins). Since 2016, Aramark expanded the number of local food vendors, extended compost collection on campus, and as previously stated, widened the variety in vegan and vegetarian options ("Food \& Recycling,” 2011; “What We're Doing,” 2019). More recently, a reusable take-out container program began in the Ville Grill (discussed in more detail below) to allow students to have a to-go meal, which creates little (if any) waste ("Now Offering TakeOut," 2019).

Since 2010, a former graduate student and current philosophy professor, Brian Barnes, has collected and processed compost near campus and offers the finished soil product to the community ("Composting," n.d.). Brian recounted the progression of his composting site during an informational interview (Appendix A). He found an unused lot owned by the University, along with dumpsters that were no longer needed, and received permission to gather organic matter on this site. At first, Brian's composting operation 
worked with a local non-profit, called Breaking New Grounds, but unfortunately, the organization closed down in 2012. Since then, Brian faced a few difficulties in maintaining the compost operation; fortunately other organizations were able to provide the necessary support to keep it afloat. The compost program works closely with the Garden Commons on campus, locating collection bins next to the garden and supplying nutrient-rich soil.

Brian began collecting plant-based materials (i.e. no meat or dairy) from the Ville Grill and a few other locations on campus. The Ville Grill contribution was short-lived because the university switched to a company able to process compost on a larger scale and include all food products. Heine Brothers helped sustain Brian's program by increasing their contribution and providing payment, which allowed Brian to hire a student intern. In 2014, a pilot program collected compost in a U of L residence hall, and for the following year, the program expanded to all residence halls on campus ("Composting," n.d.). Housing decided to discontinue compost collection due to a low participation rate and issues with odors (J. Mog, J. Jensen). As of 2019, Brian receives compost from Garden Commons, as well as the Math and Theater departments. The majority of this compost remains plant-based since the open-air, hand-turning style of this operation presents challenges in preventing bacteria formation from meat and dairy. Brian is expanding collection beyond campus to local residents by supplying an on-site collection bin open for anyone to drop off organic matter and offering to pick up from people's houses. As the only community composting site available for Louisville residents, Brian endeavors to expand composting practices and spread knowledge about this form of waste diversion. 
As an alternative solution to wasting unspoiled food, in 2018 a few students began a Food Recovery Network (FRN) chapter on campus. The Food Recovery Network is a student-led organization, which started at the University of Maryland in 2011 and expanded to 230 chapters as of 2018 ("Fiscal Year," 2018). FRN works to recover edible food that would otherwise be wasted and bring it to local agencies supplying food for those in need ("FAQ," 2017). At U of L, student volunteers collect food from locations interspersed among academic buildings and a residence hall on campus_-including Einstein's, the Starbucks inside the library, and less frequently from the Marketplace and POD stores (E. Kurtz). These volunteers then transport the food to the local emergency services agencies, St. Vincent de Paul and the Cabbage Patch Settlement House, or a local environmental non-profit, Louisville Grows, which also runs a food pantry, or a few other locations depending on the time of day and type of food (E. Kurtz).

In January 2019, a food pantry opened on campus, called the Cardinal Cupboard, borne from the collaboration between a couple student volunteers, the Student Leadership Coordinator in Student Involvement, and a few others (E. Kurtz). The cupboard is located on the third floor of the Student Activities Center (SAC) and is free to all students, faculty, and staff. The pantry is tied to the FRN because it is considered a place to donate food, and many of the same volunteers sustain both programs (E. Kurtz). At the end of the spring 2019 semester, Aramark advertised for students to spend extra flex points in POD stores (where individually packaged food and other goods are available, similar to a convenience store) to buy food and donate it to the cupboard. Student volunteers must be present for the pantry to be open, which may hinder some people's ability to browse if the hours do not align with their schedule. A sign posted on the door of the cupboard 
informs people where they can go (elsewhere in the SAC) to gain access by asking someone who has a key to the room. However, some people in need may not feel comfortable taking these extra steps to attain food.

While the University and Aramark advocate for sustainability, there seem to be roadblocks and difficulties in making larger strides. Recent budget cuts delayed the university's Climate Action Plan, which set goals to reach carbon neutrality by 2050 (“Annual Reports,” 2018; "Climate Action Plan,” 2018). Regarding food waste, a lack of clear messaging to students about how much the university cares about sustainability perhaps leads to challenges with participation when implementing initiatives to reduce waste. Another inadequate area is open communication and shared priorities among constituent departments, administrators, and students while introducing new programs. For example, the failed compost collection in housing could have benefitted from more collaboration and close interactions between housing, the sustainability coordinator (Justin Mog), and students in the designated residence halls.

\section{The Student Experience}

The majority of first year students live in what are called "traditional" halls and suite-style residence halls. These halls offer "community kitchens," although the website does not specify the number of locations on every floor, every other floor, or only a few for the building. Even though the majority of first year students may not have cooking skills, the Honors' Residence Hall Director commented that she sees students often use the kitchens (with only located on every floor) (M. Fluharty).

In deciding where to eat, students may be influenced by a variety of factors. Dining options in the SAC, in addition to Subway and Twisted Taco, offer quick to-go 
meals if students are in between classes or other activities on campus (J. Jensen).

Depending on an individual's meal plan, the Ville Grill may be a way to save flex points if they have meal swipes available, or the SAC could help save meal swipes (more on meal plans below) (L. Langston). Several residence halls are located near the Ville Grill (while others are close so the SAC), and students may prefer to walk a shorter distance for food (M. Fluharty) (see map in Appendix C). Hours of operation can affect choice as well since some students tend to stay up late doing schoolwork, and the Ville Grill closes at 8 p.m. (M. Fluharty).

Resident Assistants (RAs) run programs for students in the halls they oversee, guided by specific learning outcomes (J. Jensen, L. Langston). RAs have discretion over specific activities, as long as they meet one of the five learning outcomes-wellness, life skills, campus resources, diversity and inclusion, and sense of belonging —only two of which potentially pertain to food-related topics. Wellness could include a program on nutrition, and life skills might cover a cooking activity. However, since RAs have flexibility, it is not a guarantee all students will learn about nutrition or cooking from hall programming. A recent addition to programming in residence halls is a service requirement, which RAs were tasked with completing twice each semester (L. Langston). Sustainability-related programs could fulfill this service requirement, including composting with Brian or events during Ecolympics in the Spring. The Program Coordinator for Residence Education (L. Langston) suggested service options to RAs using the Engage, Lead, Serve Board (ELSB), which is a student organization coordinating activities and volunteer opportunities on campus and in the community ("ELSB," n.d.). Aramark employs a nutritionist who is a source for students to learn more 
about food and eating healthy (E. Trahan). The nutritionist will run programs or help with tabling on occasion, providing the opportunity to answer questions from students, along with offering one-on-one coaching sessions (E. Trahan).

\section{Meal Plans}

Full time students are automatically enrolled in meal plans, whether they live on campus or commute, and everyone has the freedom to change their meal plan early each semester. The $\mathrm{U}$ of $\mathrm{L}$ Dining website describes every meal plan option and what is available for each student based on where they live (see Appendix B). Students living in traditional or suite-style buildings have fewer options for their meal plans compared to students in apartments or commuters. Meal plans consist of swipes (counting as one meal) and flex points (considered equivalent to dollars), to be used at most dining location on campus. The plan in which on-campus residents are automatically enrolled is deemed by Aramark the optimal plan to fulfill a student's needs. There are plans costing less and offering fewer meal swipes with more flex points than the automatic plan. Aramark and the university seek to ensure that students will have enough flex points and meal swipes to get through the semester (E. Trahan, B. Knaster). Aramark is also a business trying to sell a product, which is why they emphasize upgrading when advertising to students the ability to change their meal plan (E. Trahan).

Most meal plans combine swipes and flex points, although a couple of options solely consist of flex points. As the name implies, flex points allow more flexibility in choosing what to eat from dining locations, and they can be used in more locations than meal swipes. As previously stated, students may decide where to eat based on their meal plan's swipes to points ratio. If one has to use flex points to eat in the Ville Grill, it may 
feel more expensive than eating, for example, at Chick-fil-A (J. Jensen). Two plans catered toward first years have unlimited meal swipes, which includes unlimited access to the Ville Grill at any point during the day. The majority of first years have this unlimited access, which is why dining administrators say they make up most of the Ville Grill's population (E. Trahan).

Meal plans are standard on college campuses. When $\mathrm{U}$ of $\mathrm{L}$ sought a new contract for the food service provider, the meal plan requirement for students was included because a company would not want to build restaurants on campus without knowing this will be compensated (B. Knaster). Aramark created the various meal plans, and the University's Executive Director of Business Services indicated trust in Aramark's ability to use their resources as a national food service provider (including on many college campuses) to determine meal plans that will see students through the end of each semester (B. Knaster, E. Trahan).

During orientation and welcome week, when soon-to-be first year students are becoming familiar with campus, Aramark heavily campaigns and gives student information about meal plans_-including advertising the option to upgrade their plan (E. Trahan). At events and tabling, Aramark employees encourage students to follow their social media accounts, where they also post about meal plans and upgrading. In the social media posts, they provide a link to the form needed to change their plan; however the website from the link provides no information about the meal plan options, rather it offers another link for students to investigate the alternative plans. Whether or not students explore meal plan choices for themselves is difficult to ascertain, and meal plan 
information can easily go unnoticed by first year students moving in to residence halls and starting classes.

\section{The Ville Grill}

The Ville Grill opened in the fall of 2010, under Sodexo's tenure, as the first allyou-can-eat dining hall on campus. People pay a flat rate (or use one meal swipe) to eat in the Ville Grill, and then have the freedom to eat as much as they want while inside. As part of the all-you-can-eat deal, leftover food cannot be packaged to-go, so any food left on a person's plate becomes waste. Upon entering the Ville Grill, ample seating is the left and right, with an island of several food stations (few of which are self-serve) located straight ahead. Past the tables on either side are more stations, many of which are served by staff. Along the back wall, leading up to the dish return conveyor belt on the opposite corner from the entrance, are self-serve stations for waffles, toast, and drinks. From the beginning, it was open to the public and completely tray-less to help reduce food waste, with small-scale composting at first that expanded to nearly all food waste. Initially, the population dining in the Ville Grill was largely students and employees at U of L, and they continue to comprise the majority of patrons; though as more people come to campus for tours or construction jobs, the number of community diners has grown (M. Watkins).

In addition to having no trays, there are signs posted around the Ville Grill saying “Taste, Don't Waste" and signs above the dish return area displaying the number of pounds diverted from landfills (although the number remained unchanged during the school year 2018 to 2019) (see Appendix D). In the fall of 2018, Aramark launched a reusable to-to container program ("Now Offering Take-Out," 2019). Participants pay an 
up-front fee to enroll in the program and receive a key tag, which can then be used to trade in for a reusable container. Students with an all access meal plan are automatically enrolled, although many do not pick up their key tags (E. Trahan). To get a new container, the empty, used one must be brought back, and there are other restrictions to ensure that people take only a single meal's worth of food.

Brian Barnes picked up the compostable materials from the Ville Grill at first, during which time meat, dairy, and bones were not collected. Then Sodexo began contracting with an industrial composter, which eventually switched to the current compost processor, Westrock. With the move to a contracted composter, more materials can be collected for compost, including meat, dairy, and the more recent introduction of compostable cups. Almost everything that might become waste in the Ville Grill is compostable, except for one product. At the waffle station, students use a plastic cup to fill with batter and pour into the waffle iron because this particular cup ensures that batter does not overflow out of the iron. This plastic cup and items that are occasionally offered in individual, single-use wrapping are the only non-compostable materials in the Ville Grill.

\section{Ville Grill Population}

As previously mentioned, it is assumed that the majority of students in the Ville Grill are first years. The assumption rests with expectations about the meal plan availability for freshmen. However, if the proximity of residence halls to the dining hall are considered, it is likely the dining population is more diverse. The two residence halls closest to the Ville Grill are Louisville Hall and University Tower Apartments (UTA). Louisville Hall houses first year students, but UTA is home to mixed years and each 
room contains a kitchen ("Louisville Hall," n.d.; "University Tower Apartments," n.d.). That students in UTA are less likely to have a meal plan with unlimited swipes and can cook in their rooms does not exclude them from dining in the Ville Grill regularly. As Nikolaus et al. (2018) and Belasco (2008) point out, convenience is an important factor when deciding what to eat, and the Ville Grill's location (next door) could not be more convenient.

A Sodexo exercise called Weigh the Waste furnished opportunities to learn about the dining population and the nature of food waste. Aramark's Sustainability Coordinator and the Sustainable Dining Intern now run this event regularly in the Ville Grill, where students discard leftovers into a bin sitting on a scale before returning their dishes to be cleaned. Throughout the fall and spring semesters, I weighed plate waste in one to twohour increments during lunch or dinner to learn more about the nature of food waste. As I conducted more weighing events, I saw more food wasting patterns worth noting. I began writing down the gender of people as they were returning dishes, which allowed me to depict the dining hall's population.

People visiting campus or University employees seem more likely to eat in the Ville Grill during lunch, whereas the population during dinner appears mainly to consist of students. From observations, it is difficult to predict a certain type of student who eats in the Ville Grill— the crowd appears similar to that of the overall student population. However, I learned after noting visible gender during several Weigh the Waste events and taking a sample of class levels that there are differences between the students in the Ville Grill and the general University population. While weighing waste during lunch in March, the Sustainable Dining Intern (Patrick Reeder) and I randomly asked 50 students 
what their year in school is. To avoid bias, we asked students who were scraping food off their plates as well as those returning clean plates. The sample results are: 62 percent freshmen, 14 percent sophomores, 18 percent juniors, 4 percent seniors, and 2 percent graduate students. As suspected by administrators, a majority of diners are first years; however sophomores and juniors are present as well.

After taking notes on the gender of people when they returned their dishes, I noticed a heavy majority of males even though the full-time undergraduate population for the fall of 2018 was 52 percent female and 47 percent male ("U of L Enrollment," 2018). Table 1 shows the data collected during Weigh the Waste about gender, showing a considerable disparity between males and females. To calculate the number of males and females, I tallied each gender from my notes for each day I made these observations.

Then I entered the totals into an excel sheet and calculated the percentages of females and males for the total count from each day. The number of females is consistently around a third of the population (and males around two thirds), with little change between the fall and spring semesters. As I elaborate in the conclusions, the preponderance of males raises multiple questions for future research.

\begin{tabular}{|c|c|c|}
\hline \multicolumn{3}{|c|}{ Gender from Weigh the Waste } \\
\hline Date & Percent female & Percent male \\
\hline $10 / 29 / 18$ & 35 & 65 \\
\hline $11 / 5 / 18$ & 39 & 61 \\
\hline $1 / 23 / 19$ & 28 & 72 \\
\hline $2 / 6 / 19$ & 32 & 68 \\
\hline $3 / 20 / 19^{*}$ & 32 & 68 \\
\hline Average & 33.2 & 66.8 \\
\hline
\end{tabular}

Table 1. Gender from Weigh the Waste. Notes: *On $3 / 20$, the gender data is used from the class sample we collected instead of from the longer period of waste weighing, which is how the rest of the data was collected. 


\section{Weigh the Waste}

Taking advantage of Weigh the Waste allowed me to observe people's different reactions to being asked to dump their waste; although this method presents several challenges, discussed below. In addition to visible gender, I noted the various food being discarded. I also recorded interesting comments people made and other potential influences on waste or the population, such as the weather.

Challenges in collecting the waste. At first, I conducted waste weighing by myself, and it proved arduous to simultaneously take the aforementioned detailed notes. Then, I coordinated my schedule with Patrick Reeder so that he could help run these events. Patrick's involvement resolved a few of the difficulties I had on my own, such as the people who could not hear me call out asking to discard their food and waste into the bin. Patrick's deep voice more often cuts through whatever people are listening to with their earbuds and generally catches people's attention more easily. Some challenges persisted after Patrick and I began working together. Once or twice during a session, someone would say they do not have food on their plates (when we can clearly see that they do) or someone says "no thanks" as they put their food-waste-ridden dishes onto the conveyer belt. Periodically, when several people converge at the dish return at once and we repeatedly ask for everyone to scrape their plates if they have waste, a few in the bunch either ignore or cannot hear us as they return plates without emptying them. I also noticed the occasional person who had a stack of at least two plates only empty the one on top (when I could see food left on some of the dishes underneath). Several instances such as these led to our inability to capture 100 percent of the waste accumulating during our time in the Ville Grill. 
From the beginning, non-food waste has been included in what people throw into the bin. When I first helped at the event with the Aramark Sustainability Coordinator, she allowed the inclusion of napkins as they add very little weight, and it does facilitate the pace of dumping, especially when a line starts to form. Also, we ask people to discard any food left on their plate, and sometimes this will include fruit peels (which is not considered food waste). Even though the organic matter we weighed was not purely "food waste," the majority of the weight comes from food waste since napkins are very light and fruit peels were collected only a few times during a session (if at all).

Limitations in interpreting data. People in the Ville Grill retrieve food and return their plates in various flows and patterns. Some wait until they finish their meal and drop off all their dishes in one trip before leaving. Others get one or two plates at a time, eat however much food from them, and then return those dishes before going for more food. Some people may do a combination of these patterns, or behave differently depending on how much time they have to eat. Because of these variations, some people stop by the dish return area multiple times during Weigh the Waste. I tried to note the people I saw more than once, but could not do this systematically enough to modify my data. Furthermore, some people who I saw more than once had a clean plate during one trip and food waste on the next. Lastly, I cannot always attribute waste to the individual who carried the plate because some people would clear all the dishes for their table. Food waste and behaviors. After every weighing session, I typed the date and time-frame into an excel sheet, along with the total weight. Because of the variations in the exact number of minutes spent weighing waste, I calculated the average weight per minute for each session. I found this the optimal method to regularize the weight data for 
comparability, as opposed to average weight per person, because I did not count the number of people in the Ville Grill at each session, as well as the limitation regarding people approaching the dish return discussed above. Table 2 shows the weight data from each weighing session. Several factors could contribute to the fluctuations in the amount of waste generated during lunch or dinner. During the two days with the highest average weight per minute (October $26-0.67$ pounds per minute and November $5-0.66$ pounds per minute), I noted large groups of people who were not students (likely visitors on campus) dining in the Ville Grill and contributing to the waste weight. As I began to take more notes on what people were wasting, I noticed that vegetables are the most often wasted food group — which ranged from a few pieces of broccoli to a whole serving of green beans. This observation accords with other studies stating vegetables and fruits are the most wasted food groups among consumers (Conrad et al., 2018; Mekonnen \& Fulton, 2018). 


\begin{tabular}{|c|c|c|c|c|}
\hline \multicolumn{5}{|c|}{ Food Waste Weighing Data } \\
\hline Date & Time Frame & $\begin{array}{c}\text { Total Time } \\
\text { (in minutes) }\end{array}$ & $\begin{array}{c}\text { Total Weight } \\
\text { (in pounds) }\end{array}$ & $\begin{array}{c}\text { Average waste } \\
\text { per minute } \\
\text { (lb/minute) }\end{array}$ \\
\hline $8 / 30 / 2018$ & $11: 30 \mathrm{am}-1: 05 \mathrm{pm}$ & 95 & 46 & 0.48 \\
\hline $9 / 24 / 2018$ & $11: 50 \mathrm{am}-1: 00 \mathrm{pm}$ & 70 & 23 & 0.33 \\
\hline $9 / 27 / 2018$ & $11: 33 \mathrm{am}-1: 00 \mathrm{pm}$ & 87 & 43 & 0.49 \\
\hline $10 / 1 / 2018$ & $11: 50 \mathrm{am}-1: 00 \mathrm{pm}$ & 70 & 42 & 0.60 \\
\hline $10 / 1 / 2018$ & $5: 19 \mathrm{pm}-6: 30 \mathrm{pm}$ & 71 & 14 & 0.20 \\
\hline $10 / 26 / 2018^{*}$ & $11: 40 \mathrm{am}-12: 42 \mathrm{pm}$ & 62 & 41.5 & 0.67 \\
\hline $10 / 29 / 2018^{*}$ & $5: 00 \mathrm{pm}-6: 32 \mathrm{pm}$ & 92 & 23 & 0.25 \\
\hline $11 / 5 / 2018^{*}$ & $11: 48 \mathrm{am}-1: 00 \mathrm{pm}$ & 72 & 47.5 & 0.66 \\
\hline $1 / 23 / 2019^{*}$ & $12: 03 \mathrm{pm}-1: 20 \mathrm{pm}$ & 77 & 33.5 & 0.44 \\
\hline $2 / 6 / 2019^{* \times}$ & $12: 00 \mathrm{pm}-1: 08 \mathrm{pm}$ & 68 & 23 & 0.34 \\
\hline $3 / 6 / 2019^{*}$ & $12: 00 \mathrm{pm}-1: 30 \mathrm{pm}$ & 90 & 28 & 0.31 \\
\hline $3 / 20 / 2019^{*}$ & $12: 10 \mathrm{pm}-1: 30 \mathrm{pm}$ & 60 & 28 & 0.47 \\
\hline $4 / 15 / 2019^{* *}$ & $11: 30 \mathrm{am}-1: 39 \mathrm{pm}$ & 129 & 33.5 & 0.26 \\
\hline
\end{tabular}

Table 2. Food Waste Weighing Data. Notes: *Sustainable Dining Intern, Patrick Reeder, helped with the event. ${ }^{\times}$At the beginning of February, some changes were made to how waste weighing events would be run, and Ellen trained the staff on encouraging students to taste dishes. ${ }^{* *}$ On 4/15/2019, there were events in the Ville Grill to promote Earth Day, including weigh the waste, and while Patrick was not there to help, a volunteer helped during this event.

Students and other Ville Grill diners reacted in multifarious ways when asked to add the food from their plates into the bin in front of us. Some people mentioned feeling bad about having waste and a few would say "I don't normally waste very much" as they dumped food into the bin. Several people looked embarrassed by having Patrick and I watch as they scrape food off their plates. Occasionally, a person looked disgustedly at the food scraps piling up inside the bin, and a couple people said "gross" as they try to avoid touching their own food waste while tossing it in. One day, as a group of collegeaged males were ignoring (or possibly could not hear) me asking them to dump their plates, Patrick spoke up, saying “C'mon boys, don't be scared," which grabbed their attention and resulted in most of their plates being emptied into our bin. No one was happy about having food waste - the only emotions we witnessed were negative ones. 
While conducting informational interviews about the food system on campus, a few mentioned that Weigh the Waste events helped raise awareness. For instance, the Program Coordinator for Residence Education (L. Langston) mentioned that one day she was eating in the Ville Grill while we were weighing waste, and it made her think about her habits.

During the observations, I noticed a few problematic behaviors. First, not everyone is aware of the composting, or if they are aware they do not fully understand what is compostable, because I witnessed people dump food or napkins from their plates into a trash can located along the route most people take to return their dishes. Signs are posted informing people to not dump food in this trash can, but people do not look at them, especially if they are coming from a certain direction when the signs are less obvious. This trash can is for the non-compostable waffle batter cups. The Sustainability Coordinator informed me she is looking for an alternative, but they currently use these cups because it is more important that waffle batter does not spill and constantly create a mess at this station. It seems like a simple solution could be to put a lid on the trash can as the large opening may be too inviting for people who are less aware of composting and see the opportunity to quickly scrape their plates as they walk by.

The second dilemma I noticed, which sometimes contributes to the problem with tossing compostable waste into the trash can, is that a lot of non-students will eat in the Ville Grill. Opening the Ville Grill to the public can benefit students in a certain way because the revenue from people paying to dine in (who are not on a meal plan) can help lower the prices of meal plans (according to Mark Watkins). However, when people are new to the Ville Grill, they seem less likely to be aware of the composting. For example, 
one day when I was in the dining hall to conduct interviews, I noticed a large group of students from Portland Elementary. It also happened to be a very busy day, so I was standing near the dish return watching the herds of people funneling toward the conveyor belt to drop off their plates. The elementary school students were getting ready to leave, so a stream of kids was returning plates all at once. One of the Portland students was standing near his peers, telling them to throw their food in the trash can. Eventually one of the chaperones told this kid they did not have to this because she knew they could leave food on their plates. This may be a bit of an outlier, but the point is that not everyone who visits campus and dines in the Ville Grill is aware of the dish return procedures.

University staff and students have achieved several successes in sustainability, particularly in addressing food insecurity and composting on campus and in the community. However, greater sustainability is hindered by unclear priorities and separation between university entities. The Ville Grill holds a unique position as the only location where all waste could near full diversion from landfills, yet the all-you-can-eat style presents as contradictory to sustainability principles. Despite the signs encouraging people to taste food and participate in composting, the behavioral patterns suggest people do not consider the consequences of taking more than they will eat, especially if they are newcomers. The buffet-style and restrictions on food leaving the building put the responsibility on the diner to only take as much as they will eat to further reduce food waste. This raises questions about the ways student patrons perceive food waste and reflect on their own behaviors around food. 


\section{CHAPTER 3:}

\section{WHAT DO STUDENTS HAVE TO SAY ABOUT FOOD WASTE?}

I interviewed undergraduate students in the Ville Grill to find out their perspective regarding food waste on campus and in general. During a three-week period in April of 2018, I approached people as they stopped by the dish return area to inquire if they were willing to participate. In total, I conducted 60 semi-formal interviews; 54 are included in the analysis. This chapter reviews the process of analyzing interview responses, followed by a description of the demographic characteristics of the sample and how it compares to the general undergraduate population. Next, I will examine the interview responses, sorted into four topics — students' dining hall preferences, what generates food waste, their attitudes toward food waste, and how to reduce food waste - and connect themes to the literature. The interview agenda is as follows, after which I asked about participants' age, major, year in school, hometown, and ZIP code.

1. Where do you often eat on campus?

2. What do you think happens to your food waste when you throw it away? (following Nikolaus et al., 2018)

3. Think back over the last 24 hours. Why did you find yourself disposing of food? (following Nikolaus et al., 2018; Campbell-Arvai, 2015)

4. How do you feel about wasting food in general? (following Whitehair et al., 2013) 
5. It is important to me to reduce the food waste on campus. 1 - strongly disagree, 2 - disagree, 3 neutral, 4 - agree, 5 - strongly agree (Marais et al., 2017)

6. What do you do in your day-to-day life to reduce your food waste? (following Campbell-Arvai, 2015)

7. What would make it easier for you to waste less food on campus? (following Nikolaus et al., 2018)

\section{Coding and Collating Responses}

After each interview session, I typed my handwritten interview notes, and entered each response into an Access database. To begin organizing the demographic data, I read through each interview and entered the age, year, major, and hometown of each student into an excel file. Viewing the distribution for each of these characteristics facilitated grouping ages, majors, and hometowns. Utilizing the university's website, I organized each student's stated major into its school or college ("Schools and Departments," n.d.). Since three-quarters of the sample are from Kentucky, I grouped in-state hometowns by regions employing state maps (“West Kentucky," n.d.; "Kentucky County Map,” 2019).

I read through each interview and identified some of the common themes that seemed to be expressed in each of the responses. I then grouped the responses for each question by these emergent themes. After this initial round of thematic coding, I could examine all the items in that group, and then revisit my original categorizations to be more inclusive for responses. Using these broader thematic categories, I read each interview a second time and placed each response into a category (or, depending on how much a participant had to say for a certain question, a few categories). A second iteration also allowed for reconsideration and adjustment of answers that appeared ambiguous at 
first. For example, one of the initial groups for question 6, "avoid letting food go bad," included the response "don’t buy things I won’t eat fast enough." On a second review, this small category was divided among two refined categories- - "get what I know I can eat," and "finish my plate or eat all my food," — based on the action suggested from each response. I moved the above response to "get what I know I can eat," because it involves a consideration of what this person will or will not eat.

During the interview analysis, I found several interviews as insufficient in most of the responses, which is why the sample in the following discussion includes 54 out of the 60 interviews conducted. Most of the removed interviews are from early in the threeweek period before I developed probes to elicit more detailed responses. To ensure none of the removed interviews were included in my final count in the tables and figures below, I reviewed each interview question one more time. From this final revision, I entered the number of responses in each category into an excel sheet to calculate the percentages and create the following graphs.

\section{The Sample: Demographic Characteristics}

At the end of each interview, I asked a few questions about the participant to find out their year in school, age, major, and where they grew up. I also noted the visible gender after concluding each interview. The gender ratio is similar to the data from waste weighing sessions, with 69 percent of the sample male and 31 percent female (Figure 2), while Weigh the Waste averaged 66.8 percent male and 33.2 percent female (Table 1). I counted the number of males and females in the dining hall before most interview sessions, and on a few days I counted again before leaving. In the Ville Grill during interviews, the average proportion was 63 percent male and 37 percent female. To 
determine if the sample strategy was effective, I began noting the gender of people I approached but did not interview. Including both those I interviewed and those I did not, the gender ratio is 61 percent male and 39 percent female. While all these figures demonstrate a close representation of the Ville Grill, it is clear more males than females agreed to be interviewed.

The distribution of year in school is slightly different than the sample taken during waste weighing. Nevertheless, the class most represented is freshmen with 70 percent of the interviewees (Figure 3), while the earlier sample comprised of 62 percent freshmen. The age distribution of participants parallels the year in school since the majority of people were 19 years old (54 percent) (Figure 4). Figure 5 shows the distribution of majors in their respective colleges. The majority of students in the sample are from Kentucky, so there is a single category for the 14 people (26 percent) from outside the state, including 3 who are from other countries. As a point of reference, about 78 percent of the incoming class for the fall of 2018 enrolled as a Kentucky resident ("U of L Incoming,”2018). The hometown regions are presented in Figure 6.

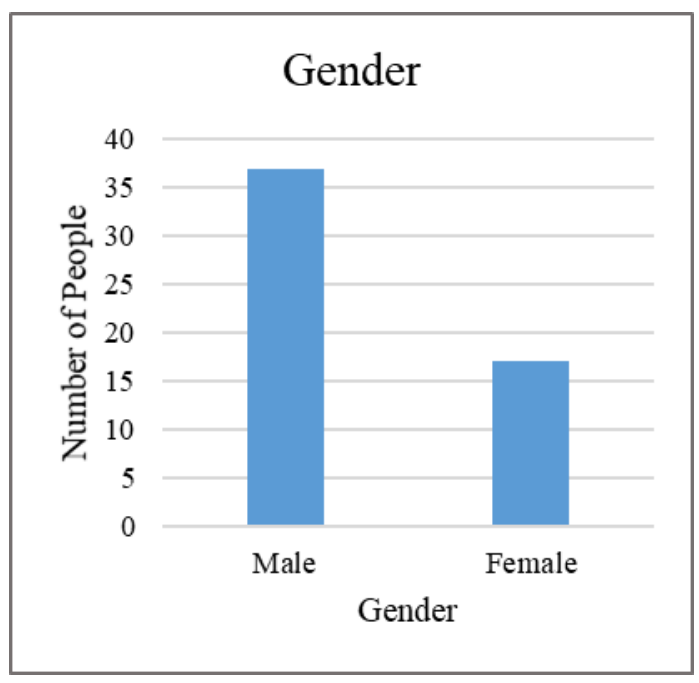

Figure 2. Gender Distribution.

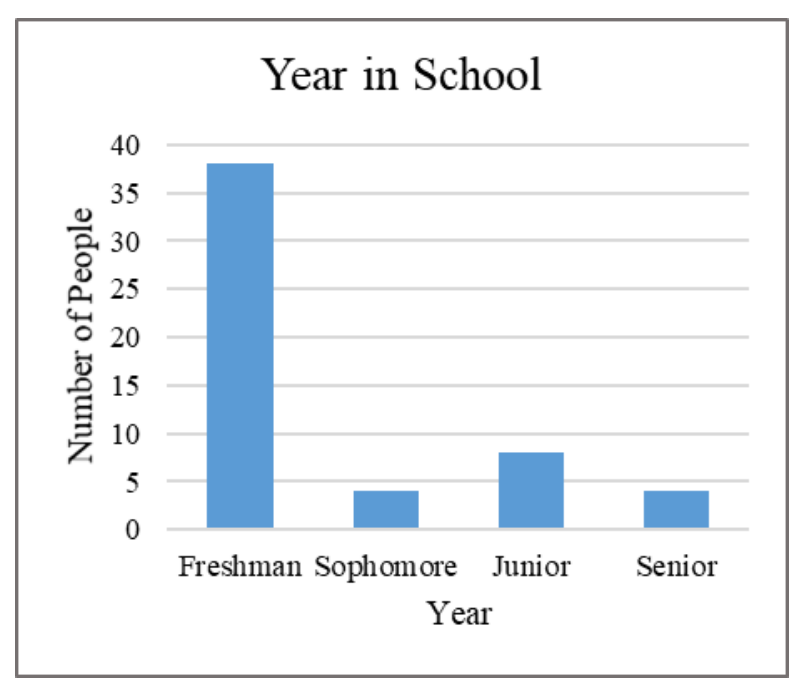

Figure 3. Year in School. 


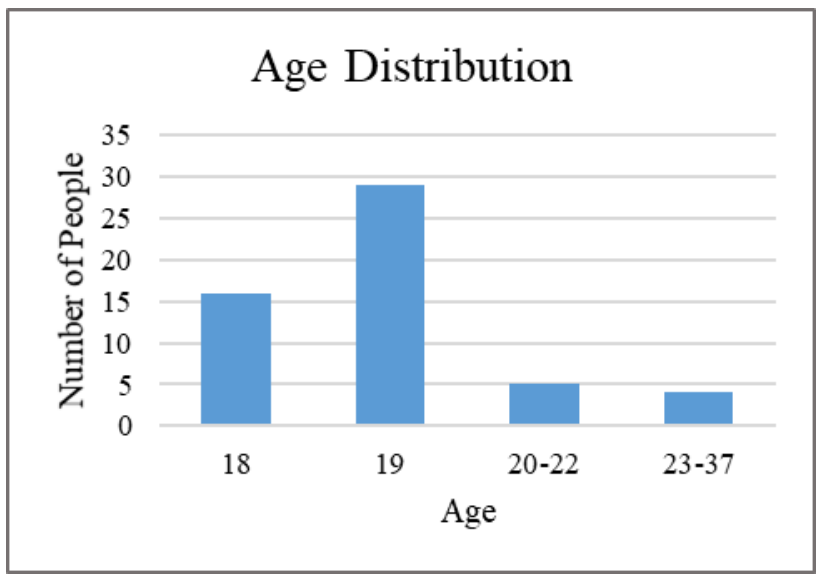

Figure 4. Age Distribution.

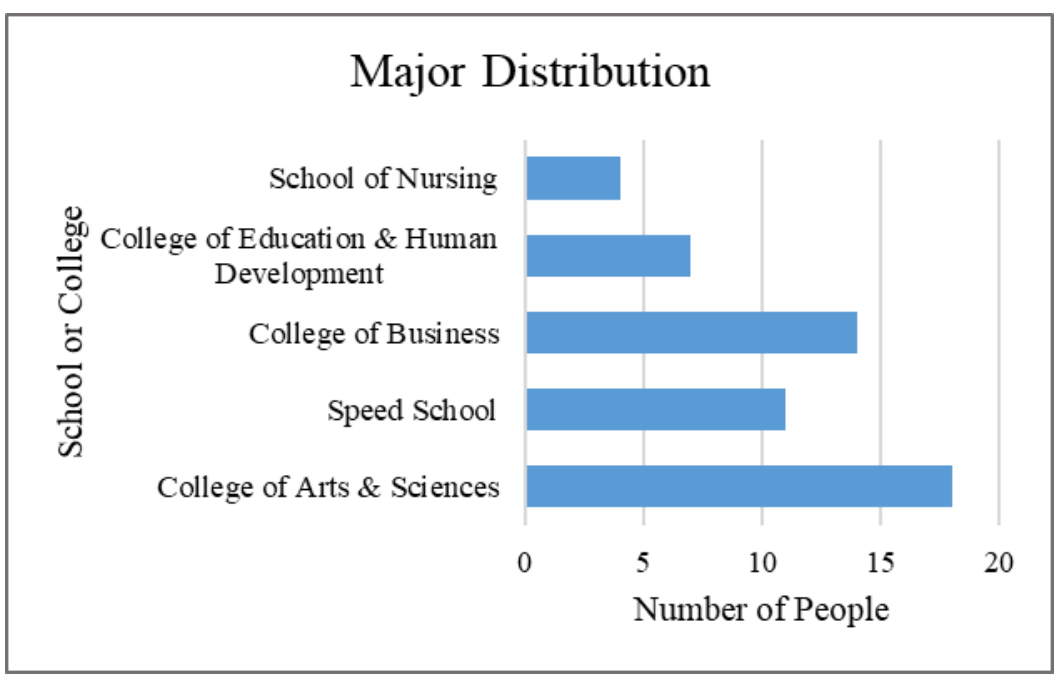

Figure 5. Major Distribution.

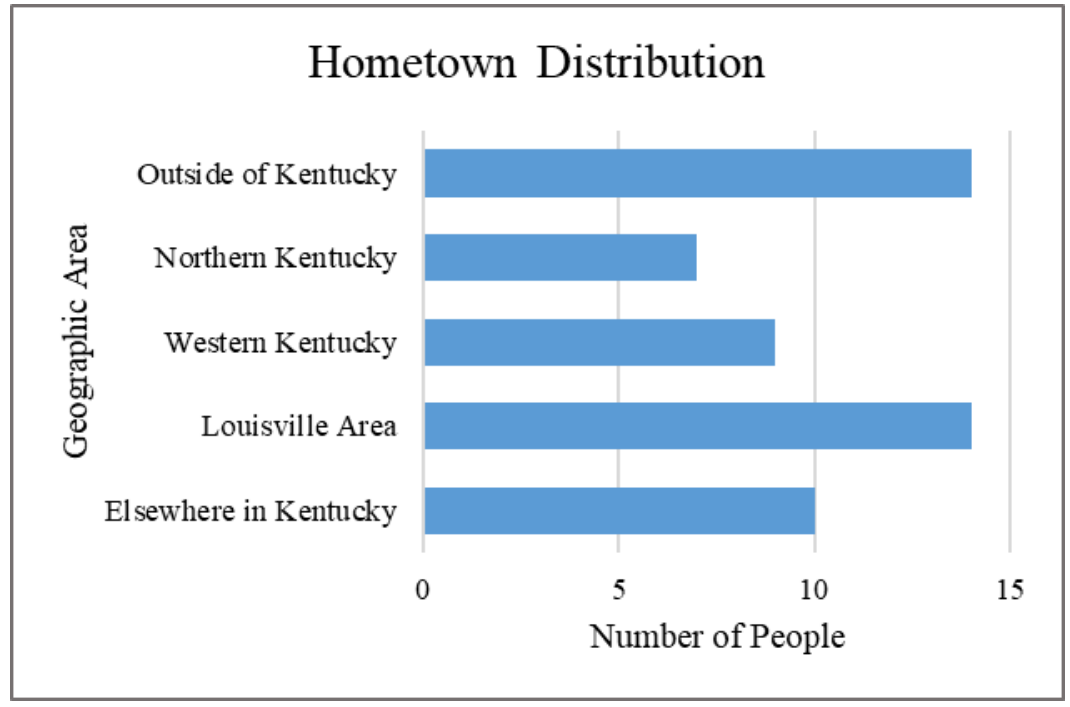

Figure 6. Hometown Distribution. 


\section{Dining Hall Preferences}

The first question defines where students eat as a way to determine the experience and knowledge base for the remaining questions. Table 3 shows the array of dining preferences for students in the sample. I did not define "often" when posing the question to students, so when sorting the responses, I applied the definition to be more than once a week. If a participant only listed one place, I asked if there is anywhere else they eat regularly. Since the interviews were held in the Ville Grill, I expected most students to eat there often. Two people who said they mainly eat in the Ville Grill commented that it is basically free, and two others pointed to its convenient location (close to their residence hall). If not in the Ville Grill, most students eat in the SAC, where several options are located such as Chick-fil-A, Wendy's, Panda Express, and the Marketplace. Among the 13 percent of respondents who do not often eat in the Ville Grill are people who live in further residence halls or off campus, one person who has an issue with gluten, and others who seem to prefer cooking their own food or dining elsewhere on campus. (See map in Appendix C). 


\begin{tabular}{|c|c|c|c|}
\hline \multicolumn{4}{|c|}{ Question 1 Responses } \\
\hline Response & Notes and Examples & Count & $\begin{array}{l}\text { Percent } \\
\text { of total }\end{array}$ \\
\hline Ville Grill & $\begin{array}{l}\text { - Listed first or second, or specified as twice a } \\
\text { week or more }\end{array}$ & 47 & $87 \%$ \\
\hline SAC & $\begin{array}{ll}\text { - } & \text { Listed the SAC (or a location therein not } \\
\text { listed below) } \\
\text { - } \\
\text { - } & \text { Specified Chick-fil-A (11) } \\
\end{array}$ & 34 & $63 \%$ \\
\hline Twisted Taco & & 8 & $15 \%$ \\
\hline $\begin{array}{c}\text { Eat at } \\
\text { home/cook }\end{array}$ & - Includes dorm or off campus & 7 & $13 \%$ \\
\hline $\begin{array}{l}\text { Not as often in } \\
\text { Ville Grill }\end{array}$ & $\begin{array}{l}\text { - Once a week, } 4-5 \text { times a month } \\
\text { - "not often" } \\
\text { - } 4^{\text {th }} \text { time ever }\end{array}$ & 7 & $13 \%$ \\
\hline Other & Subway, POD, Card Towne, Einstein's & 8 & $15 \%$ \\
\hline
\end{tabular}

Table 3. Question 1 Responses. Question posed: "Where do you often eat on campus?"

Similar to arguments made by Belasco (2008) and Nikolaus et al. (2018),

convenience is a high priority when deciding where to eat, which could mean the Ville Grill or the SAC depending on the individual. The Assistance Director of Residential Life commented that students may prefer the SAC because of its to-go options, which are more convenient when in a hurry. Students may find the Ville Grill more convenient because of its location, or depending on their meal plan, it may feel like the cheaper option. The meal plan does seem to have a significant influence on who eats in the Ville Grill and how this changes during the semester. One interviewee remarked how he recently (around the time of the interview) was not often eating in the Ville Grill, but before he ran out of flex points, he would frequent it once or twice a day. Alternatively, a couple people commented on not eating in the Ville Grill unless invited by a friend, and one of these people elaborated to say his friend needed to use up their flex points before the semester ended. Question one's interview responses and related comments indicate 
that meal plans and living situation, combined with convenience, have a significant influence on where people eat.

\section{Awareness of Waste Management}

The second interview question served to discover student's awareness about what happens to their waste on campus. It follows Nikolaus et al. (2018), who argue if students were more aware of the consequences of food waste, they may take more action to reduce their waste. After the first several interviews (most of which are not included in the final sample), I realized the need to distinguish between the Ville Grill and other places on campus. I clarified if their initial response related to the Ville Grill, and then asked what they thought about other places on campus. Students' responses about what happens to their waste in the Ville Grill are shown in Figure 7a, and the responses about other places on campus are in Figure 7b. Regarding the Ville Grill, 52 percent of participants demonstrated some awareness that their waste is composted. Although, several people voiced uncertainty or doubt, such as "I hope it gets composted," or "they claim to reuse it in some way." A few people specified that composting only occurs after we weigh the waste, which is interesting because this is the only time people eating in the Ville Grill see their waste put into a compost bin. Interviewees also expressed uncertainty about the fate of waste elsewhere on campus with comments such as "probably goes to landfill," or "I guess garbage." One person specifically noted that he does not think about what happens to his waste, while another commented later in the interview how he never thinks about any of the questions. 

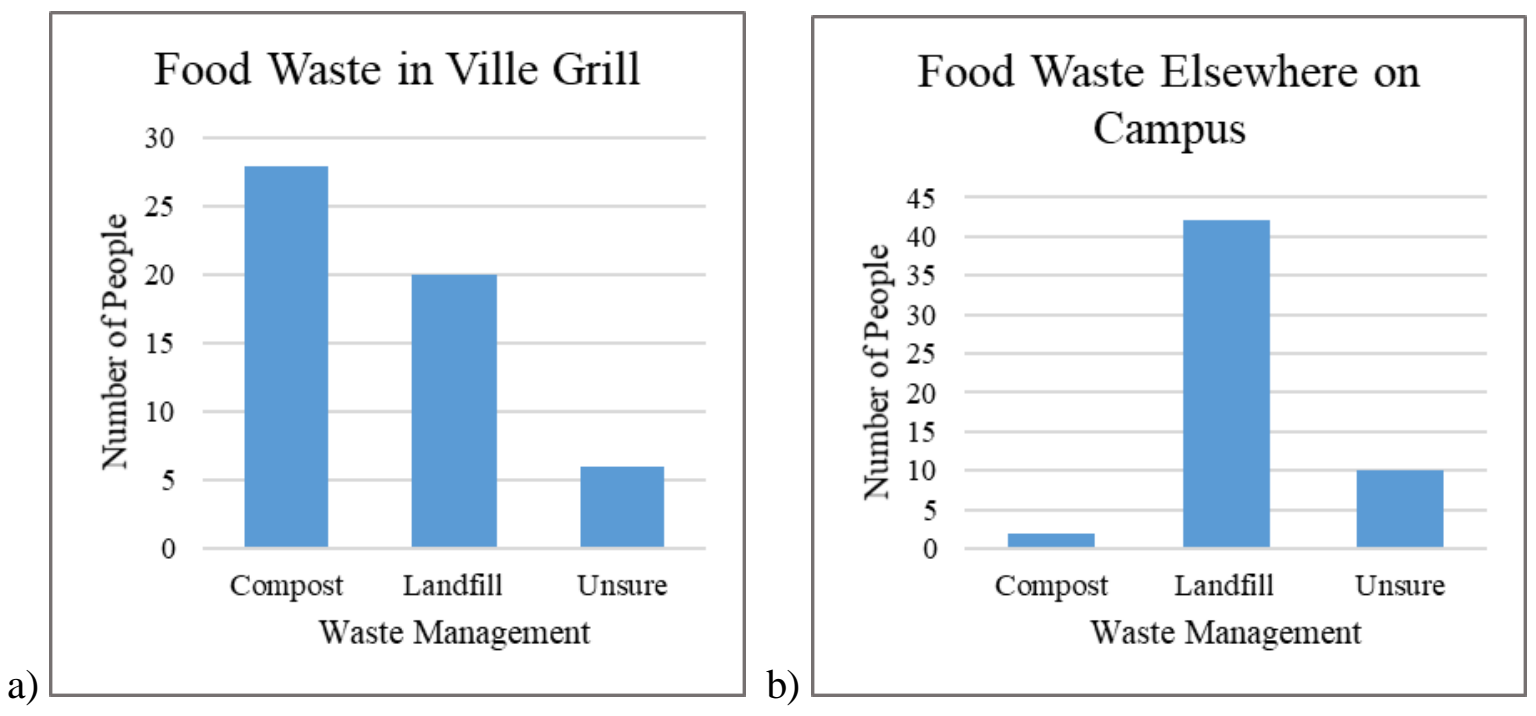

Figure 7. a) Responses for food waste in the Ville Grill, and b) Responses for food waste elsewhere on campus. Question posed: "What do you think happens to your food waste when you throw it away?"

The majority of students know (or guessed correctly) about food waste management and how it differs between the Ville Grill and other locations on campus, with 52 percent realizing the Ville Grill composts and 78 percent noting elsewhere landfills. As previously stated, part of the 52 percent who identified composting in the Ville Grill believe it only occurs after weighing, which attests to the observation from Nikolaus et al. (2018) that visibility can increase awareness. Conversely, more people are unsure of what happens to their waste from other places on campus (19 percent) than from the Ville Grill (11 percent). While students did reveal some levels of awareness, the gaps in knowledge and uncertainty regarding what happens to their waste on campus emphasizes this area for improvement in working to reduce food waste.

\section{What Generates Food Waste}

The third question seeks to ascertain some of the reasons why students waste food, similar to previous studies asking questions to understand reasons behind participants' behavior (Nikolaus et al., 2018; Campbell-Arvai, 2015). The responses for 
question 3 are present in Table 4. Some people provided multiple reasons, so their response is divided into multiple categories. The most common response, variously expressed, related to satisfying their appetite before finishing their plate. Some people articulated over-anticipating their level of hunger. Others commented that the portions were too big (some specified in the Ville Grill, and some specified other locations), which led to wasting food.

The second most common response relates to personal preferences in taste or specific parts of food. For example, a couple of people talked about their dislike of pizza crust, which they will always discard. Problems with taste or quality also encompass responses about disliking a particular dish, whether because of seasoning or unexpected flavor. Twenty-eight percent of participants first responded that they have not wasted in the past 24 hours, or that they do not normally waste much food. Several people also noted issues with letting food spoil, which led to waste. Most people, however, seem to be wasting food because of incorrectly anticipating how much food they will eat (which could be caused by a range of factors) and personal preferences about food. 


\begin{tabular}{|c|c|c|c|}
\hline \multicolumn{4}{|c|}{ Question 3 Responses } \\
\hline Response Category & Examples & Count & $\begin{array}{l}\text { Percent } \\
\text { of Total }\end{array}$ \\
\hline Because I got full & $\begin{array}{l}\text { - "I wasn't hungry as I thought I was" } \\
\text { - "didn't finish it," } \\
\text { - "I got too much of it" }\end{array}$ & 35 & $65 \%$ \\
\hline $\begin{array}{l}\text { Problem with taste, } \\
\text { quality, or specific } \\
\text { part of food }\end{array}$ & $\begin{array}{l}\text { - "I didn't like it," and "I didn't like the } \\
\text { taste" } \\
\text { - "There was no more chicken in the } \\
\text { taco, just tortilla, so I threw that away" } \\
\text { - "Decided I didn't want to eat" }\end{array}$ & 23 & $43 \%$ \\
\hline $\begin{array}{l}\text { Have not wasted or } \\
\text { generally don't waste } \\
\text { very much }\end{array}$ & $\begin{array}{l}\text { - "I usually eat all my food" } \\
\text { - "Not a whole lot in the past } 24 \text { hours" }\end{array}$ & 15 & $28 \%$ \\
\hline $\begin{array}{l}\text { Because food went } \\
\text { bad }\end{array}$ & $\begin{array}{l}\text { - "Old expired food" } \\
\text { - "I let a lot of food go bad in my fridge" }\end{array}$ & 7 & $13 \%$ \\
\hline Other reasons & $\begin{array}{l}\text { - "I wanted to try something else," } \\
\text { - "I'm trying to watch my figure" }\end{array}$ & 4 & $7 \%$ \\
\hline
\end{tabular}

Table 4. Question 3 Responses. Question posed: "Think back over the last 24 hours. Why did you find yourself disposing of food?

\section{Attitudes toward Food Waste}

The fourth and fifth questions reveal students' attitudes regarding food waste in general and on campus. Question 4 pertains to individualized attitudes and is modeled after questions from the survey conducted by Whitehair et al. (2013). The further questions about why students feel the way they do help in discovering what influences attitudes toward waste. The explanations for how students feel are displayed in Figure 8, and the elaborations on those feelings are in Table 5. In explaining their response, some participants were ambiguous while others gave several reasons. As such, two interviewees excluded from the second part of question 4 and several are counted in two categories.

The majority (75 percent) of people have generally negative feelings toward food waste, although there is variation in the degree of their feelings. Some students evinced strong negative feelings by saying "I hate it," or "it's horrible." More frequent answers in 
this category are "it's bad," and "I don't like it." While still on the side of negative, 17 percent of participants expressed a qualified feeling toward food waste-similar to findings from Ahmed et al. (2018) where students expressed concern but did not consider food waste on a regular basis. One student commented "I feel guilty, but it's not a very high priority," and another remarked, "it depends on the amount," and went on to explain that he feels bad if he's wasting a lot of food, but not as bad if it's only a little bit. For some people, the guilt or bad feeling is not at the forefront of their mind or depends on the situation. A few people (8 percent) voiced their indifference toward food waste, most of them conveying they rarely thought about it.

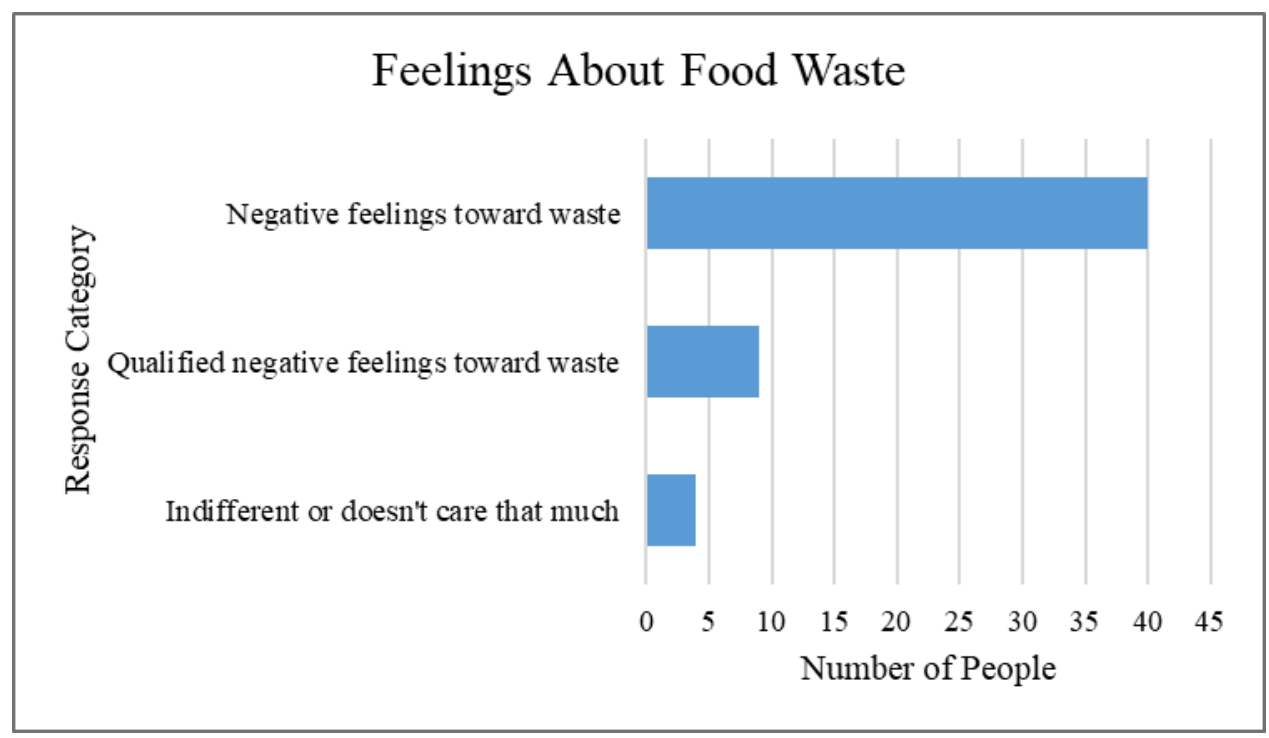

Figure 8. Question 4 Responses. Question posed: "How do you feel about wasting food in general?" 


\begin{tabular}{|c|c|c|c|}
\hline \multicolumn{3}{|c|}{ Reasons for Question 4 Response } & \\
\hline Response Category & Examples & Count & \\
\hline $\begin{array}{l}\text { Other people don't have } \\
\text { as much access or are in } \\
\text { need }\end{array}$ & $\begin{array}{l}\text { - "I think about people in other countries } \\
\text { who aren't as fortunate to eat every } \\
\text { day" } \\
\text { - "A lot of people are malnourished, } \\
\text { don't get enough food" } \\
\text { - "It's the principle of the matter" }\end{array}$ & 19 & $35 \%$ \\
\hline How I was raised & $\begin{array}{l}\text { - "Growing up, you didn't waste food," } \\
\text { - "I was raised in another country," } \\
\text { - "I was raised not to waste food" }\end{array}$ & 13 & $24 \%$ \\
\hline Waste of resources & $\begin{array}{l}\text { - "It's a waste of money, waste of time, } \\
\text { waste of resources," } \\
\text { - "I try not to because I paid for it," }\end{array}$ & 12 & $22 \%$ \\
\hline $\begin{array}{l}\text { It could be put to better } \\
\text { use or repurposed }\end{array}$ & $\begin{array}{l}\text { - "Could give leftovers to people who } \\
\text { need it" } \\
\text { - "I wish there was an efficient way to } \\
\text { ship food to people that don't have it," } \\
\text { - "I know it could be used better" }\end{array}$ & 9 & $17 \%$ \\
\hline $\begin{array}{l}\text { Why I don't feel too } \\
\text { bad }\end{array}$ & $\begin{array}{l}\text { - "Food is in abundance, if I don't eat it } \\
\text { it's not a big deal" } \\
\text { - "[in Ville Grill] I don't always think } \\
\text { about it because it's not my food" } \\
\text { - "If I waste I can get more" }\end{array}$ & 9 & $17 \%$ \\
\hline
\end{tabular}

Table 5. Reasons for Question 4 Response.

Similar to arguments from Ahmed et al. (2018) (along with Benson et al., 2018; Breewood, 2019; Martin-Rios et al., 2018; Barret 2014), 35 percent of students feel bad because of an unclear connection between food waste and how other people are hungry or in need of food. Several interviewees mentioned people in other "third world" countries who do not have as much access to food, and one person acknowledged "it's the principle of the matter." The second most common response pertains to how people were raised, with many participants describing parents inculcating in them the need to clean their plates and not waste food. Several people (22 percent) also pointed to wasting resources, whether it was the environment, time, or money_most of whom conveyed wasting money as the main concern, which relates to Ahmed et al. (2018) describing how people 
may care more about waste if they connect it to cost (also discussed in Nikolaus et al., 2018). This category also indicates that when people have knowledge of the environmental consequences, they may care more about food waste (Nikolaus et al., 2018).

The category "it could be put to better use," is distinguished from the first because people made a more distinct connection to how reducing food waste could help people. Many respondents mentioned bringing leftover food to those in need as opposed to simply referring to the principle of food waste existing at the same time as hunger and food insecurity. One student expressed a desire to use her extra flex points to buy food and bring it to homeless people around Louisville. This category also includes a couple of students who indicated how if people were more cognizant of the amount of food they put on their plate, more food would be available to other people in the dining hall (i.e. the plate waste could be put to better use as a serving of food for someone else). The last category contains many reasons why participants do not feel too bad, or have no feeling of guilt, such as "in the US, there's surplus," and "food is in abundance; if I don't eat it, it's not a big deal." A couple of people recognized they feel indifferent because they are in a privileged position in society. The most unexpected remark in this group came from someone who does not feel bad wasting food specifically in the Ville Grill because “it's not my food." The majority of students recognize environmental and social effects of food waste, which seem to influence their negative feelings toward it.

The next question to determine students' attitudes toward food waste is a Likertscale ranked statement, modeled after a survey question in the study by Marais et al. (2017). The distribution of rankings for question 5 are presented in Figure 9. None of the 
participants disagreed with the statement about reducing food waste on campus, demonstrated by zero responses for 1 or 2 . Eleven students ( 20 percent) said they felt neutral, a few of whom explained how they feel they currently do little to reduce food waste. Others suggested there is not much they can do, echoing Zhang et al. (2017) in respect to a lack of personal responsibility toward environmental issues. One person revealed they do not think about reducing campus food waste, even though they described disliking wasting food personally and being raised not to waste.

Half of participants agreed that reducing food waste on campus is important to them. Corresponding to findings from Ahmed et al. (2018) an Nikolaus et al. 2018) that students perceive profuse amounts of waste in the US, several people expressed a perception of abounding food waste on campus. A few students commented on having higher priorities than reducing food waste, although they nonetheless agreed that it is important. Almost a third of interviewees strongly agreed with the statement. Some explanations mirrored response categories for the second part of question 4, with a couple of people feeling bad because others are in need of food. One person noted the importance of diverting waste from landfills, while another mentioned being raised to not waste food. Most students either agreed or strongly agreed that it is important to reduce food waste on campus, which parallels the generally negative attitude most have, as determined by the previous question. 


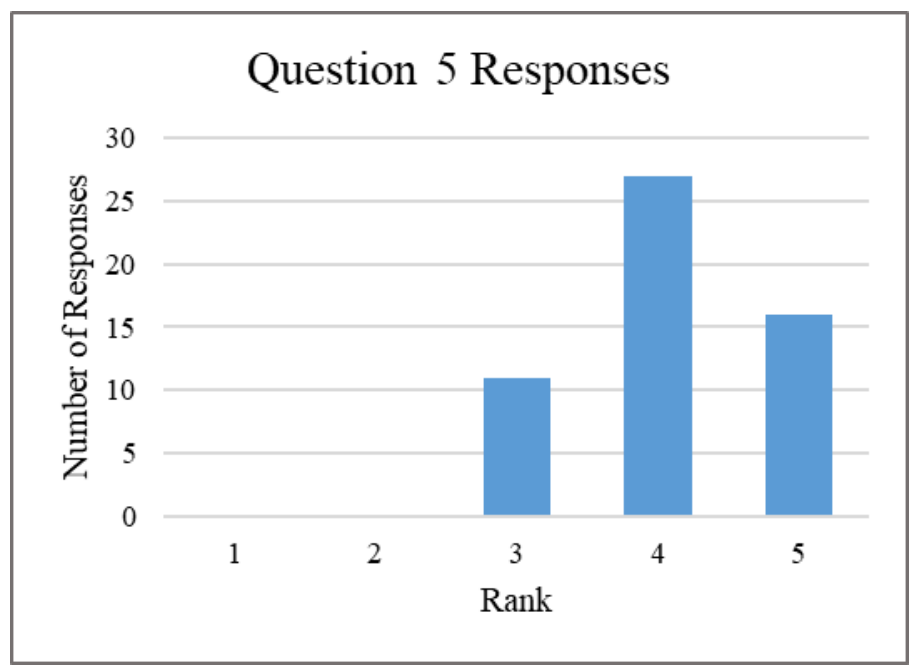

Figure 9. Question 5 Responses. Statement posed: "It is important to me to reduce the food waste on campus." 1 - strongly disagree, 2 - disagree, 3 - neutral, 4 - agree, 5 strongly agree.

\section{How to Reduce Food Waste}

The last two questions are meant to point paths toward possible solutions for reducing waste. First, I asked participants about what they do to reduce waste on a personal level in question 6 . This inquiry was inspired by the survey conducted by Campbell-Arvai (2015) who asked students to identify their behaviors that help the environment (e.g. recycle, eat less meat, compost food scraps). Identifying individual behaviors can lead to targeted solutions since students implement these effective strategies. Participants' behaviors in reducing individual waste are displayed in Figure 10. Many students listed several actions they take in reducing waste, so they are represented in more than one category. Fifty seven percent of respondents reduce their food waste by taking what they know they can eat, need, or like. This category encompasses endeavors to control portions, such as asking for a small amount, not taking more food than they are sure they can eat, and cooking the proper portion at home. It also covers responses related to only taking food they know they enjoy, and buying just enough food they can eat before it spoils. 
The second most popular behavior (at 31 percent) pertains to finishing their plate or eating all their food. It differs from the first category because responses emphasized obtaining an empty plate more than anticipating how much they need before filling it. Saving or repurposing food contains several responses about saving leftovers, as well as people who will offer leftover food to friends before wasting it, confirming Nikolaus et al.'s (2018) argument about how sharing food reduces food waste. Consciousness of appetite or hunger involves considering one's appetite before seeking out food. For example, one student expressed "I eat only when hungry," and another specified eating only at mealtimes. The category also covers awareness of one's hunger while eating, such as eating one plate and then deciding if they want more food. All of these responses can help with individual waste reduction. However, they also likely require consideration and reflection, which as several students indicated in previous questions is something they do not often practice.

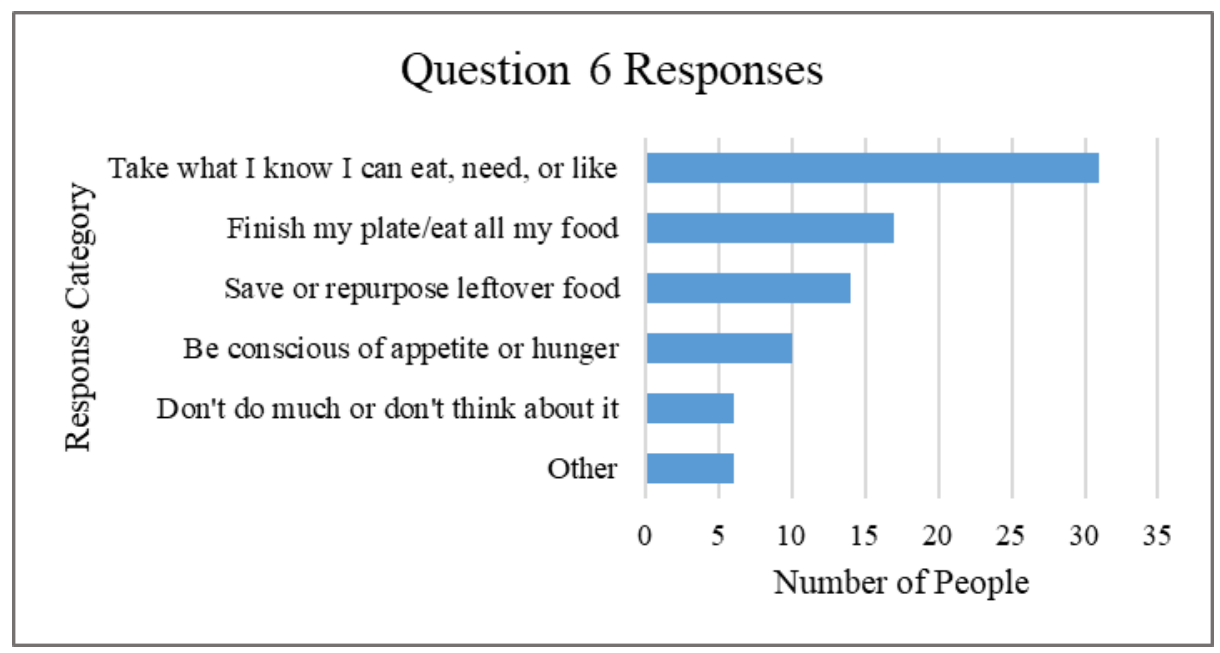

Figure 10. Question 6 Responses. Question posed: "What do you do in your day-to-day life to reduce your food waste?"

The final interview question seeks to discover any structural factors that could support students in reducing their food waste on campus, along with identifying any 
barriers that might be present. This question follows Nikolaus et al. (2018) in their discussion with students about possible interventions to reduce food waste. Figure 11 displays the diverse answers for question 7. In previous questions, some students emphasized how little waste they create, so I added to the last question with "you or other students" because I found early on that these interviewees would simply repeat "I don't waste." Several people provided multiple suggestions, which means they were put in more than one category. The responses are more varied than previous questions, with the largest group containing 46 percent of participants. Server-side or structural suggestions comprise many propositions for smaller portion sizes (some specific to the Ville Grill), as well as providing tastings across campus (although a few mentioned this for the Ville Grill, where tastings are currently available). Many of the responses in the diverting food waste category emphasized one example of a structural barrier — there are no bins for students to send their food waste to compost, comparable to findings from Zhang et al. (2017) where students do not sort waste due to lack of access to proper receptacles.

Almost a quarter (24 percent) of students commented on self-awareness about appetite or hunger, which entails being aware of one's own hunger and controlling portions. Several people in this category mirrored their response for question 6. Individual effort or responsibility (comprising 19 percent of participants) is distinct from the previous group because it emphasizes the accountability each person has in reducing their food waste rather than one's decisions around food. Many students in this category proposed educating more people and raising awareness about the importance of reducing food waste, indicating this would help increase participation in food waste reduction efforts. One person specifically said that reducing waste is something that is up to the 
individual. Other responses include a few comments about the Ville Grill currently doing well in reducing waste and controlling portion sizes, along with some outlying recommendations. Most people perceive some potential structural adjustments that could reduce food waste. Although a small number of students mentioned it, individual responsibility is an important element in maintaining the civic participation necessary for the continuity of some improvement, like increasing the number of compost bins around campus.

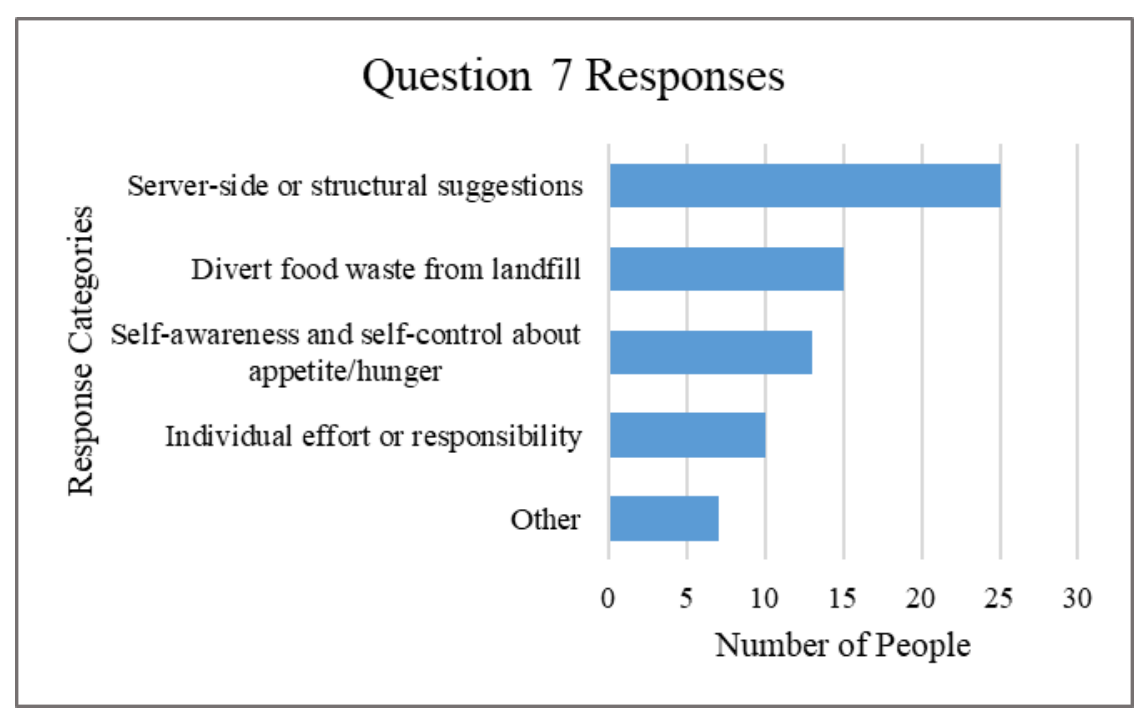

Figure 11. Question 7 Responses. Question posed: "What would make it easier for you to waste less food on campus?"

\section{Conclusion}

Fifty four undergraduates in the Ville Grill answered questions to help me understand their perspective as $\mathrm{U}$ of $\mathrm{L}$ students regarding food waste on campus and in general. Although the sample is not perfectly representative of the undergraduate population, it nonetheless provides insight into what influences students' behavior and attitudes. In making decisions around food, convenience and personal preference appear to be the main considerations. Students are somewhat aware of food waste management practices on campus, but more visibility may further improve awareness. Most students 
hold negative attitudes toward food waste; however their sporadic attention to it could be contributing to waste production. There are several paths to reducing food waste suggested by these interviews, both on a personal level and structurally. Individual tactics require reflection and taking personal responsibility, while structural changes involve more flexibility in serving sizes, offering tastings, and expanding student-facing compost collection. Understanding how students are making decisions and what they contemplate in respect to food can steer the direction toward more effective waste reduction strategies. 


\section{CHAPTER 4: \\ DISCUSSION, RECOMMENDATIONS, \& CONCLUSION}

Understanding the student perspective through interviews highlighted three main findings related to their behavior around food waste: the importance of convenience; healthy eating habits and mindfulness; and forethought about waste. I discuss each of these themes, along with how they contribute to the literature on student waste behavior. Examining the students' responses in the context of the University of Louisville's food system illuminates limitations in our ability to progress food waste reduction, specifically obstacles related to transparency and communication among university offices and with students. Specific changes the University can make to enable further waste reduction and diversion are presented. Lastly, I review limitations for this study and paths for future research.

\section{Interview Discussion}

About halfway through the interview, one student remarked "these questions are weird; it's not something I really think about." This lack of thought for food waste is a common theme throughout the interviews, although it often appeared to be implicit, in contrast to this blatantly candid comment. Interesting as this observation is, the more pertinent themes relate to those considerations students focus on, including convenience, health, and appetite. Students demonstrated their knowledge of consequences of food 
waste, thus underlining the missing piece in their awareness as a lack of consistent reminders of those consequences.

Convenience matters when students make decisions about food (i.e. where, when, and what to eat). A few students emphasized the ease of going to the Ville Grill because of its proximity to their residence hall. In the Ville Grill, picking out what food to put on one's plate is quite a task with many different options available. New dishes are frequently offered, and everything is prepared fresh by chefs, so the exact recipe of regular dishes may change. Because students do not know if they will like something, the Ville Grill encourages them to taste dishes before getting a whole serving (although some options such as burgers or waffles cannot be sampled). People do not consider how they may end up wasting food when picking out what to eat. Many reasons students gave for wasting food related to a lack of contemplation before selecting food, such as "I got too much of it," "my eyes were bigger than my stomach," and one student "just didn't think about it." The way students answered questions suggested that they prioritize convenience and personal preference (or identity) over responsibility, confirming Belasco’s (2008) argument about people's decision-making around food. Even though they do not appear to consider food waste when selecting food, some introspection can prompt little or not waste.

Students revealed two types of concerns that can induce less food waste: healthfulness and mindfulness. Many students mentioned healthy eating habits in answer to what they do to reduce waste, such as "get a little bit at a time and get more if I need more," and "avoid bingeing, only eat when hungry." A few people specifically commented how their responses to this question have more to do with trying to eat 
healthy than reducing food waste. Many students alluded to a sense of mindfulness or self-control about choosing when to eat and how much to eat as a way to reduce food waste on campus. For example, several commented along the lines of "only get what I think I'll eat, don't get extra," and "if I know I'm not hungry enough to eat a whole meal, just wait." The Associate Director of Residential Life emphasized how arduous it is to convince students who are indifferent about environmental issues to suddenly care; therefore understanding that some students contemplate health and appetite suggests alternate routes for education campaigns than environmental or social consequences of food waste. The manner in which students considered the interview questions and posed their responses indicates the significance of intervening with education and awareness campaigns before students pick out what to eat. Previous studies on student behaviors and food waste do not focus on healthy eating habits or how students make a decision before retrieving food (Whitehair et al., 2013; Nikolaus et al., 2018; Pinto et al., 2018; Marais et al., 2017). Based on my study, I found the most important point at which waste can be reduced is before it lands on a plate, and many responses such as "don't get food I won't finish," and "know how hungry I am," highlighted this notion.

Students evidently care about food waste when prompted to think about it. However, several commented how they do not often think about food waste or do not highly prioritize it—for example, "I don't usually think of the repercussion," and "there are other things on campus that are more important to me." Aside from the signs encouraging students to taste food and informing them of composting in the Ville Grill, there is little advertising pertaining to food waste (see Appendix D). One effective interaction is Weigh the Waste because many said with more confidence that the Ville 
Grill composts during this event (compared to those who hope and think the Ville Grill composts every day). Telling students directly about composting and letting them see the waste accumulation is a critical tool for raising awareness about food waste, confirming the argument from Nikolaus et al. (2018) that increasing visibility boosts concern about waste. While signs may be effective for reducing a small portion of waste, as found by Whitehair et al. (2013), it is not enough to reach zero waste. They conclude that frequent reminders are necessary to engage those underlying beliefs, and as such, engaging interventions (including Weigh the Waste) in addition to signage could further reduce food waste.

\section{U of L Food System Revisited}

Students' behaviors around wasting food can be understood in the context of the University's food system and the environment configured for them. Through informational interviews with several University staff and the Aramark Sustainability Coordinator, I characterized the University's food system, discussed in chapter 2. Investigating the food system illuminated a couple of challenges that may hinder further food waste reduction, namely, communication difficulties, and unclear motives and priorities. Applying the student interview responses from chapter 3 to the food system discussion offers specific suggestions of what the University and Aramark can do to improve.

The University of Louisville's current system does not easily facilitate changes or implementation of sustainability initiatives. The opening of the food pantry exemplifies many of the hurdles present, including the difficulty in finding the right location and challenges with communication. To secure a location, several different people had to be 
contacted, and at one point when the room was nearly set, the plans fell through so the process had to begin again. The most prevalent communication challenge was explaining the meaning of sustainability to several people who had somewhat skewed perceptions of it (E. Kurtz). The University's vision for sustainability, found on the sustainability page, is "to create a university that is itself a living laboratory for sustainability and a campus community that leads by example and educates as much by what we do as by what we say,” (“U of L Sustainability,” 2019). A relatively small group of people at U of L take on most of the burden to establish and support programs to reduce and divert waste (e.g. sustainability students, Aramark's Sustainability Coordinator, Justin Mog, and some administrators who are sustainability-minded). The housing administrators I spoke with gave the impression that anything related to food is assumed to be taken care of by Aramark. The Senior Associate Vice President for Operations does seem to care about sustainability and will discuss it with higher ups in Aramark (although not with their sustainability coordinator). This raises the question about whose responsibility it is to interact with students on a personal level about food waste as well as broader topics on food-related sustainability.

After speaking with various housing staff, it appears there is very little conversation with students about food and even less about food waste in residence halls. Granted, there are many topics housing has to choose from when programming, which is partly why RAs have discretion in creating events for their individual halls. Students can volunteer for events related to food waste, but it is difficult to determine how frequently these events are advertised and the level of participation. Outside of the Ville Grill, there is little advertising about food waste around campus. The fragmented communication and 
sense of responsibility is likely fed by having the central part of the food system outsourced to Aramark. Information outside of what is presented around campus is challenging to attain from this private company. Both Aramark and the University can improve their transparency toward students about priorities, specifically regarding food and food waste on campus.

The Associate Director of Residential Life mentioned in our informational interview how students begin forming habits while at college. Blichfeldt and Gram (2013) studied students' experiences regarding food as they transition to college and, for many, planning all their meals, where habit formation is considered an important process to reach the end of this transition phase. This notion further substantiates the need for universities to instill sustainability principles and work to solve related issues, such as food waste. Since the University wishes to integrate sustainability in every facet of campus, housing should not be excluded, as it is a critical location to model how students can reduce waste.

Housing is an important location for this education because of the more controlled environment and that students eat in their rooms, even if only occasionally. Some interviewees mentioned how they threw away spoiled food in their room, including a few who brought back leftovers and forgot about it. The Assistant Director of Residential Life's comment about often seeing pizza boxes in residence hall trash cans, implicates housing as a crucial place to learn about composting since these and other take-out containers, along with plant-based dorm waste (e.g. paper towels, napkins) are compostable. Helping students to develop habits of reducing their waste and sorting what they can to compost in their living space could instill these practices so they continue 
after they graduate. There is little research specifying how students form habits during transition; however a general study on habit formation finds that simpler tasks can become an automatic behavior (and one step closer to habit) more quickly than complex tasks (e.g. eating fruit with lunch compared to running for 15 minutes before dinner) (Lally et al., 2010). As such, the University can focus on simpler forms of waste sorting (i.e. easy user-interface with informative cues for action) as a starting point to aid habit formation.

\section{What $U$ of L Can Do}

As the main hub of food waste intervention on campus, the Ville Grill can make a few small changes to further improve waste diversion. First, the trash can into which some students and newcomers tend to scrape food off their plates could have a lid with a sign on it simply saying, "no food or napkins," (following the finding from Whitehair et al., (2013) about the effectiveness of simple messages). While some people may continue to toss napkins or food in this trash can, it could help with visitors' awareness regarding leaving food on their plates. Secondly, Weigh the Waste can be enhanced to target behavior changes further by offering positive feedback for people who have clean plates. During the spring 2019 semester, Patrick began handing out "clean plate award" stickers to those who came by with clean plates (see Appendix D). The sticker was better received by some people, while others seemed not to care. Testing different forms of an incentive aside from a sticker could potentially add to the effectiveness of this type of feedback for more people. Another tactic to refine waste weighing events, similar to how Ohio State University diverts its waste, is speaking directly to those who put napkins or food in the 
trash can to let them know that the Ville Grill composts everything, so they can leave it on their plates.

Catching the attention of people who do not think about food waste is difficult, especially if the focus is mainly on its environmental consequences. Discussing the bigger picture in education campaigns will not affect everyone, as some students commented how they do not think their small amount of waste is contributing much to the overall problem. Additionally, many students feel there is little they can do to resolve the larger issues on campus. Targeting some educational and awareness campaigns to specify healthy eating habits or increased cost to the individual and how these relate to food waste could reach those students who may care more about these topics than the environment. Several students do not consistently think about food waste but nonetheless care about the negative consequences associated with it. Greater transparency regarding what happens to waste on campus could elicit further consideration from the students who care, and it could provoke more thought from those who perhaps do not care as much about food waste.

Expanding compost collection across campus is critical to further reduce and divert the university's food waste (and waste overall). Composting is an excellent solution to divert waste from landfills and mitigate effects of climate change by reducing the amount of greenhouse gases emitted (Tonini et al., 2018; Lin et al., 2018). Studentfacing compost collection was attempted in the past, and problems like contamination and low participation led to its failure. Finding a solution to student-facing compost collection is crucial as the University's responsibility to model how students and the community can take action in complex issues like food waste (Uhl \& Anderson, 2001; 
Barlett, 2011). Collaborating with students early in the process of re-introducing compost collection could set the stage for better participation (similar to the usefulness of collaboration found by Barrett (2014) and Long et al. (2017)), along with the aforementioned education campaigns to incite a wider collective desire to divert waste from landfills.

Whose responsibility is it to instill practices that further food waste reduction? Several students suggested how each individual is responsible for reducing their own waste, yet some also expressed skepticism in other people's ability to make that effort. If the University wishes to support a living laboratory as a way to educate students, it should prioritize reaching zero waste and continue its community composting while modeling how students can reduce their own waste, even after they graduate. To burden food services with the responsibility of handling food waste is inadequate for students and the University. The silos of information sharing and limited channels of communication between groups such as housing, Aramark, university administrators, and the general body of students inhibit expansion of composting on campus and discussion of food waste in all aspects of students' experiences on campus. While outsourcing food service may be efficient in many respects for the University, perhaps this separation, at least in part, invoked these silos and fragmented senses of responsibility among University offices.

\section{Research Limitations}

One of the methods I used in gathering information was observation, which restricts the use of these findings. The student sample from interviews limits the applicability of this research, as it is not representative of all University of Louisville 
students. In addition, using the phrase "food waste" without explaining my intended meaning added ambiguity in responses. Lastly, I explain why uncertainty is present in a couple aspects of the food system investigation.

I made several observations in the process of characterizing waste and behaviors in the Ville Grill, including people's gender. I also did not ask students' gender after the interview with the other personal questions-I took note of this characteristic after they left. This opens the possibility of slight inaccuracies in the demographic profiles presented in chapters 2 and 3. The sample of students in the Ville Grill offers a glimpse into part of the students' perspective regarding food waste on campus. I was able to interview a few students who do not regularly eat in the Ville Grill. Most students in the sample live on campus and are first-years, so the results are not fully representative of all students at $\mathrm{U}$ of $\mathrm{L}$. Although there are more males than females in the sample, this closely resembles, albeit with the aforementioned qualification, the student population in the Ville Grill as determined during waste weighing events. There is no frame of reference for a representative sample of the dining hall as no demographic information about the diners is recorded by Aramark or the University. Moreover, the Ville Grill population likely changes throughout the school year-both during each semester as meal plans are used and across semesters as students explore and adapt to schedule changes. Finding a perfect representation of the Ville Grill is out of the scope of this research since visitors and employees dine there as well. Since many demographic characteristics were unknown, the interview questions were broad and do not elicit as much detailed information about this group of students as they would had a profile of a target population been available. 
I also realized that food waste itself is a highly subjective term. In retrospect, it would have been useful to develop a working definition - perhaps via a focus group before starting the interviews. There is also an element of uncertainty in some aspects of the $\mathrm{U}$ of $\mathrm{L}$ food system, as I could not get corroboration from Aramark on a few details regarding meal plans and decision-making I learned from University faculty.

\section{Future Research Recommendations}

There are many routes to continue this line of research. First, I recommend studying how people define food waste and consider what is preventable versus unavoidable waste. This could clarify where students come from when they suggest that there are higher priorities than reducing food waste and why some say it is impossible to have no food waste. I also suggest investigating the relationship between healthy eating habits and food waste to understand if it can lead to less waste. Several students suggested health-related tactics to reduce their own waste (e.g. only eating at meal times and filling up one plate at a time). However, a couple of students mentioned that they occasionally waste because they are trying to avoid overeating. Additionally, vegetables and fruits are the most often wasted food groups (Conrad et al., 2018). Studying which health-related eating habits interact with food waste reduction can bring more insight into how beneficial healthy eating can be.

Testing various methods for student-facing compost collection, such as different types of bins, signage, and locations, can equip this university and others with tools to effectively divert food waste from landfills. To incorporate compost collection in residence halls, a useful first step is to conduct a waste audit to better advertise and target the composting efforts. It is also worthwhile to examine what students currently know 
about composting and their attitudes toward it to target education campaigns before expanding collection on campus. Studying the effectiveness of increased visibility on awareness, particularly with the previously mentioned changes to Weigh the Waste, is another step to identify how students can participate in waste reduction initiatives.

Given the gender disparity in the Ville Grill, future research could more closely examine how perspectives differ based on gender. Campbell-Arvai (2015) noted that females are more likely than men to adopt pro-environmental behaviors, and Zhang et al. (2017) found females separated their waste more than males. In studying why males might behave differently than females, I recommend using Likert-scale ranked statements about attitudes regarding compost and reducing personal and campus waste. I would also include questions such as "what do you think when you see other people waste?" in addition to "how do you feel when you waste food?"

Another piece to understanding the student perspective is exploring their sense of responsibility. Some students made general comments about the responsibility of food waste being on each individual. To further investigate how students perceive the onus of reducing food waste, another line of questions could be employed. For example, future studies could ask students "whose responsibility is it to reduce food waste?" Also, to find out how to move forward in eliciting student involvement, researchers can ask if students see this responsibility as solely an individual matter, and if people should be working together to make systemic changes.

Since an overwhelming majority of students in the Ville Grill expressed negative feelings toward food waste, and for diverse reasons, segments of the student population could be targeted for future research into effective methods of behavior change. For 
example, students who were taught not to waste food growing up might be affected by messages differently than those who consider people with less access to food as a reason not to waste. As such, these various groups can be studied to elaborate on their perspective and how to elicit action from these students to further reduce waste.

Lastly, I recommend studying the servers' perspective regarding student food waste, particularly in a setting such as the Ville Grill. Understanding how staff perceive student behavior regarding waste and the servers' attitudes concerning it can give more insight to the complex intricacies and social influences in an all-you-can-eat dining halls.

\section{Conclusion}

Students are wasting food in an environment that encourages waste reduction because of how they consider food and food waste. These indications from student interviews are the importance of convenience, healthfulness and mindfulness, and sporadic forethought about waste. Mirroring Belasco's (2008) decision-making factors and argument, students prioritize identity and convenience over responsibility; however, incorporating responsibility as an equally high (if not higher) priority is essential to reduce food waste. I found healthfulness and mindfulness as prevalent reflections from students; and as such, future research focusing on how these interact with food waste can support messaging and education campaigns to incite waste-reducing behaviors. While studies emphasize the effectiveness of signage reminding students to reduce waste (Whitehair et al., 2013; Pinto et al., 2018), further steps need be taken within the Ville Grill and by the University to engage the underlying beliefs and attitudes about the serious consequences of food waste. 
The University's difficulties within its food system are understandable at this stage of incorporating sustainability into all aspects of campus. Investigating several interactions within the food system emphasized certain problems, including communication difficulties and differing priorities among University offices and staff regarding sustainability. Perhaps the biggest hurdle for progressing food waste reduction is the fragmented responsibility for educating students about food and food waste. As a university, particularly in a setting such as housing, imparting practices that can continue after graduation is crucial as students are likely forming new habits at this time. Housing is also the perfect spot for composting since many residents seem to not immediately think of it as a place for compost collection. The Ville Grill can make some minor improvement, and the University in general can incorporate more education and awareness campaigns to: 1) emphasize the non-environmental aspects of food waste, such as healthy eating habits and cost, and specifically link them to food waste, 2) be more transparent about what the University currently does with waste in general and for every dining location, and 3) highlight how compost works and its many benefits. I also suggest creating a plan to re-incorporate compost that involves collaborating with students and other stakeholders before integrating collection bins, after spreading awareness about compost.

Forty percent of food is wasted in the United States ("Save the Food," 2019). Wasted food means wasted resources from its production, as well as exacerbating the current climate crisis as many institutions, including the University of Louisville, send some portion of food waste to a landfill (Tonini et al., 2018). Social implications are largely negative as well, although how reducing food waste eradicates hunger and food 
insecurity is unclear. Universities are in a unique position to find successful solutions and solve problems such as eliciting participation in compost collection and behavior change in a dining hall setting. Using the insight from this study on how students consider food and food waste, we can take the next step to intervene before food is served and find a way to ingrain a priority for responsibility in reducing one's own food waste. 


\section{REFERENCES}

Ahmed, S., Shanks, C.B., Lewis, M., Leitch, A., Spencer, C., Smith, E. M., \& Hess, D. (2018). Meeting the food waste challenge in higher education. International Journal of Sustainability in Higher Education, 19(6), 1075-1094. https://doi.org/10.1108/IJSHE-08-2017-0127

Annual Reports. (2018). U of L Sustainability. Retrieved from http://louisville.edu/ sustainability/sustainability-council/annual-report

Apartment Plans. (2019). U of L Dining Services. Retrieved from https://louisville.campusdish.com/MealPlans/Category?cat=Apartment_Plans_92 21\&lid $=9221$

Barlett, P.F. (March 2011). Campus sustainable food projects: Critique and engagement. American Anthropologist, 113(1), 101-115. Retrieved January 24, 2019 from https://www.jstor.org/stable/41407379

Barret, N. (2014). How to stop wasting food. OECD Observer, (299), 18. Retrieved from http://echo.louisville.edu/login?url=https://search.ebscohost.com/login.aspx?direc $\mathrm{t}=$ true $\& \mathrm{db}=$ buh $\& A N=97672863 \&$ site $=$ ehost-live

Belasco, W. (2008). Food: The key concepts. New York, NY: Berg.

Benson, C., Daniell, W., \& Otten, J. (2018). A qualitative study of United States food waste programs and activities at the state and local level. Journal of Hunger \& Environmental Nutrition, 13(4), 553-572.

https://doi.org/10.1080/19320248.2017.1403408 
Blichfeldt, B., \& Gram, M. (2013). Lost in Transition? Student food consumption. Higher Education, 65(3), 277-289. https://doiorg.echo.louisville.edu/10.1007/s10734-012-9543-2

Breewood, H. (2019). What is food loss and food waste? Retrieved from https://foodsource.org.uk/building-blocks/building-block-what-food-loss-andfood-waste

Campbell-Arvai, V. (2015). Food-related environmental beliefs and behaviours among university undergraduates: A mixed-methods study. International Journal of Sustainability in Higher Education, 16(3), 279-295. https://doi.org/10.1108/IJSHE-06-2013-0071

Caprita, D.E. (2016). Reducing food waste in order to become the zero hunger generation. Competitiveness of Agro - Food \& Environmental Economy, 189-203. Retrieved from http://echo.louisville.edu/login?url=https://search.ebscohost.com/ login.aspx $?$ direct $=$ true $\& \mathrm{db}=\mathrm{a} 9 \mathrm{~h} \& \mathrm{AN}=125045488 \&$ site $=$ ehost-live

Climate Action Plan. (2018). U of L Sustainability. Retrieved from https://louisville.edu/sustainability/sustainability-council/climate-action-plan

Commuter Plans. (2019). U of L Dining Services. Retrieved from https://louisville.campusdish. com/MealPlans/Category?cat=Commuter_Plans_9221\&lid=9221

Composting. (n.d.). U of L Sustainability. Retrieved from http://louisville.edu/sustainability/ operations/composting 
Conrad, Z., Niles, M.T., Neher, D.A., Roy, E.D., Tichenor, N.E., \& Jahns, L. (2018). Relationship between food waste, diet quality, and environmental sustainability. PLoS ONE, 13(4), 1-18. https://doi.org/10.1371/journal.pone.0195405

Dining Services (2019). Retrieved from https://louisville.campusdish.com/ Ebrahimi, K., \& North, L.A. (2016). Effective strategies for enhancing waste management at university campuses. International Journal of Sustainability in Higher Education, 18(7), 1123-1141. DOI: 10.1108/IJSHE-01-2016-0017

ELSB. (n.d.). Retrieved from https://www.uoflelsb.org/

Fiscal Year 2018 Annual Report. (2018). Food Recovery Network. Retrieved from https://www.foodrecoverynetwork.org/fy18-annual-report

Frequently Asked Questions (FAQ). (2017). Food Recovery Network. Retrieved from https://www.foodrecoverynetwork.org/faq

Food \& Recycling (2011). The College Sustainability Report Card. Retrieved from http://www.greenreportcard.org/report-card-2011/categories/food-recycling.html

Glickman, T. S., Holm, J., Keating, D., Pannait, C., \& White, S. C. (2007). Outsourcing on American campuses: National developments and the food service experience at GWU. The International Journal of Educational Management, 21(5), 440-452. doi:http://dx.doi.org/10.1108/09513540710760219

Housing Options (n.d.). Retrieved from http://louisville.edu/housing/options/communities Kentucky County Map with County Seat Cities. (2019). Geology.com. Retrieved from https://geology.com/county-map/kentucky.shtml 
Kibler, K.M., Reinhart, D., Hawkins, C., Motlagh, A.M., \& Wright, J. (2018). Food waste and the food-energy-water nexus: A review of food waste management alternatives. Waste Management, 74, 52-62. DOI: 10.1016/j.wasman.2018.01.014

Lally, P., van Jaarsveld, C.H.M., Potts, H.W.W., \& Wardle, J. (2010). How are habits formed: Modelling habit formation in the real world. European Journal of Social Psychology, 40(6), 998-1009. https://doi.org/10.1002/ejsp.674

Lin, L., Xu, F., Ge, X., \& Li, Y. (2018). Improving the sustainability of organic waste management practices in the food-energy-water nexus: A comparative review of anaerobic digestion and composting. Renewable and Sustainable Energy Reviews, 89, 151-167. DOI: 10.1016/j.rser.2018.03.025

Lohnes, J., \& Wilson, B. (2018) Bailing out the food banks? Hunger relief, food waste, and crisis in Central Appalachia. Environment \& Planning A, 50(2), 350-369. https://doi-org.echo.louisville.edu/10.1177/0308518X17742154

Long, T.B., Looijen, A., \& Blok, V. (2018). Critical success factors for the transition to business models for sustainability in the food and beverage industry in the Netherlands. Journal of Cleaner Production, 175, 82-95. https://doiorg.echo.louisville.edu/10.1016/j.jclepro.2017.11.067

Louisville Hall (n.d.). Retrieved from http://louisville.edu/housing/options/communities/ suites/louisville

Marais, M.L., Smit, Y., Koen, N., \& Lötze, E. (2017). Are the attitudes and practices of foodservice managers, catering personnel and students contributing to excessive food wastage at Stellenbosch University? South African Journal of Clinical Nutrition, 30(3), 60-67. https://doi.org/10.1080/16070658.2017.1267348 
Martin-Rios, C. Demen-Meier, C. Gössling, S. \& Cornuz, C. (2018). Food waste management innovations in the foodservice industry. Waste Management, 79, 196-206. https://doi-org.echo.louisville.edu/10.1016/j.wasman.2018.07.033

Meal Plans (2019). Retrieved from https://louisville.campusdish.com/MealPlans

Mekonnen, M. M., \& Fulton, J. (2018). The effect of diet changes and food loss reduction in reducing the water footprint of an average American. Water International, 43(6), 860-870. https://doi.org/10.1080/02508060.2018.1515571

Mu, D., Horowitz, N., Casey, M., \& Jones, K. (2017). Environmental and economic analysis of an in-vessel food waste composting system at Kean University in the U.S. Waste Management, 59, 476-486. https://doi.org/10.1016/j.wasman.2016.10.026

Nikolaus, C. J., Nickols-Richardson, S. M., \& Ellison, B. (2018). Wasted food: A qualitative study of U.S. young adults' perceptions, beliefs and behaviors. Appetite, 130, 70-78. https://doi.org/10.1016/j.appet.2018.07.026

Now Offering Take-Out. (2019). U of L Dining Services. Retrieved from https://louisville.campusdish.com/LocationsAndMenus/Take-Out

Our Programs. (2019). I am Change Outreach. Retrieved from https://iacoh.com/about-us

Pinto, R. S., Pinto, R.M.S., Melo, F.F.S., Campos, S.S., \& Cordovil, C.M.S. (2018). A simple awareness campaign to promote food waste reduction in a university canteen. Waste Management, 76, 28-38.

https://doi.org/10.1016/j.wasman.2018.02.044 
Sarjahani, A., Serrano, E.L., \& Johnson, R. (2009). Food and non-edible, compostable waste in a university dining facility. Journal of Hunger \& Environmental Nutrition, 4(1), 95-102. DOI: 10.1080/19320240802706874

Save the Food. (2019). Natural Resources Defense Council. Retrieved from https://savethefood.com/

Schonberger, H. L., Boyer, R. R., \& Chase, M. W. (2018). Food-handling Behaviors of Student Volunteers in a University Food Recovery Program. Food Protection Trends, 38(4), 284-294.

Schools and Departments. (n.d.). University of Louisville. Retrieved from http://louisville.edu/academics/schools-departments

Siegrist, C. (2015). Organics Diversion in College Residence Halls. Biocycle, 56(10), 2934.

Sullivan, D. (2012). Serving up sustainable food service options. BioCycle, 53(4), 32.

Sustainable Management of Food (2017). United States Environmental Protection Agency. Retrieved from https://www.epa.gov/sustainable-managementfood/food-recovery-hierarchy

The Ville Grill. (2019). U of L Dining Services. Retrieved from https://louisville.campusdish.com/LocationsAndMenus/TheVilleGrill Traditional Plans. (2019). U of L Dining Services. Retrieved from https://louisville.campusdish.com/MealPlans/Category?cat=Residential_Plans_92 21\&lid $=9221$ 
Tonini, D., Albizzati, P.F., \& Astrup, T.F. (2018). Environmental impacts of food waste: Learnings and challenges from a case study on UK. Waste Management, 76, 744766. https://doi.org/10.1016/j.wasman.2018.03.032

Tucker, M. F. (2013). Launching a Food Recovery Network. BioCycle, 54(1), 35.

U of L Enrollment (2018). Retrieved from https://saspub.louisville.edu:8343/SASVisualAnalyticsViewer/VisualAnalyticsVi ewer_guest.jsp?reportName=UofL+Enrollment\&reportPath=/Shared+Data/Extern al+Reports/\&appSwitcherDisabled=true\&reportViewOnly=true

U of L Incoming Class Profile (2018). Retrieved from https://saspub.louisville.edu:8343/SASVisualAnalytics Viewer/VisualAnalyticsVi ewer_guest.jsp?reportName=UofL+Incoming+Class+Profile\&reportPath=/Shared +Data/External+Reports/\&appSwitcherDisabled=true\&reportViewOnly=true

U of L Sustainability. (2019). University of Louisville. Retrieved from http://louisville.edu/sustainability

Uhl, C. \& Anderson, A. (January 2001). Green destiny: Universities leading the way to a sustainable future. BioScience, 51(1) 36-42. Retrieved from https://www.jstor.org/stable/10.1641/0006-3568(2001)051[0036:gdultw]2.0.co;2 University of Louisville. (2019). The Sustainability Tracking, Assessment \& Rating System. Retrieved from https://reports.aashe.org/institutions/university-oflouisville-ky/report/2019-02-27

University Tower Apartments (n.d.). Retrieved from http://louisville.edu/housing/ options/communities/suites/uta 
Weisser, C. R. (2017). Defining Sustainability in Higher Education: A Rhetorical Analysis. International Journal of Sustainability in Higher Education, 18(7), 1076-1089.

West Kentucky County Trip Reports. (n.d.). Retrieved from http://www.cohp.org/ky/kentucky_w.html\#Trigg

What We're Doing on Campus (2019). Retrieved from https://louisville.campusdish.com/ Sustainability/WhatWeAreDoing

Whitehair, K.J., Shanklin, C.W., \& Brannon, L.A. (2012). Written messages improve edible food waste behaviors in a university dining facility. Journal of the Academy of Nutrition and Dietetics, 113(1) 63-69. DOI:

10.1016/j.jand.2012.09.015

Wright, S. (2012). Ohio State's diversion efforts reach 98\%. Waste \& Recycling News, 18(17), 4.

Zhang, H., Liu, J., Wen, Z., \& Chen, Y.-X. (2017). College students' municipal solid waste source separation behavior and its influential factors: A case study in Beijing, China. Journal of Cleaner Production, 164, 444-454. https://doi.org/10.1016/j.jclepro.2017.06.224

Zero Waste (n.d.) Facilities Operations and Development. Retrieved from https://fod.osu.edu/zero-waste

Zero Waste at Ohio Stadium. (2019). Ohio State. Retrieved from https://ohiostatebuckeyes.com/zero-waste-at-ohio-stadium/ 


\section{APPENDIX A}

\section{Informational Interviews}

Brian Barnes, Campus and Community Composter. May 14, 2019

Bob Knaster, Executive Director, Business Services. May 23, 2019

Ellen Trahan, Sustainability Coordinator for Aramark. Several meetings July 9, 2018 through June 27, 2019

Erin Kurtz, former Zero Waste Intern. May 23, 2019

Jake Jensen, Assistant Director of Residential Life. May 3, 2019

Justin Leibowitz, Associate Director of Residential Life. May 9, 2019

Justin Mog, Assistant to the Provost for Sustainability Initiatives. May 8, 2019

Livv Langston, Program Coordinator for Residence Education. May 7, 2019

Marah Fluarty, Kurz Hall Director. May 9, 2019

Mark Watkins, Senior Associate Vice President for Operations. June 6, 2019 


\section{APPENDIX B}

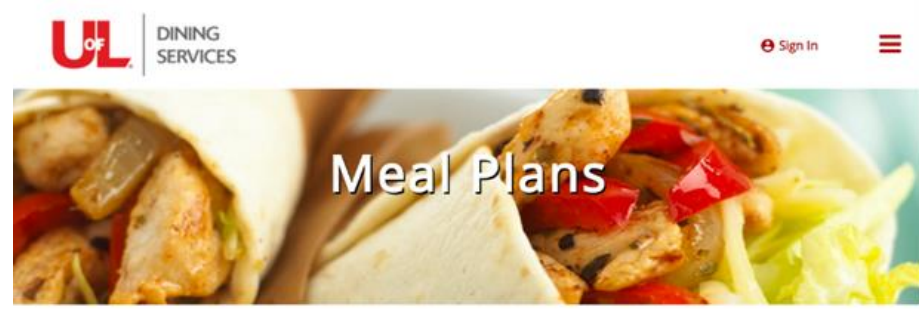

Dining on campus isn't one size fits all. Our meal plans were designed with ust a snack on the go - weve got a plan to fit every appetite.

Meal Plans

All students living on-campus (undergraduate \& graduate) or undergraduate commuters classified as full-time attending at least 9 credit Students living on campus are required to have one of the on-cal plan. meal plans. Off-campus students are required to have any of the commuter options or at least the Base Flex Plan. Every student will be automatically enrolled in the standard meal plan depending on where you live. The standard planwil cover the very basic dining needs and can be upgraded to fit all your dining needs.

Meal Plan changes are accepted online through the Cardinal Card Website. Your mea pla Meal Plan changes must we rese by the following dates:

- Fall 2019 Semester: August 29

- Spring 2020 Semester: January 16

Unused Meals expire at the end of each semester. Unused Flex Points will carry forwarc from fall to spring semester but will expire at the end of the academic year in the spring.

Weve kept what's most important to you in mind, building in the convenience, flexibility, quality, value and healthy options you deserve. Explore our meal plan options to learn more about what would be the best

\section{Our Meal Plans}

All Products

Meal plans are convenient, flexible, and loaded with options. Your meal plan includes dining locations all across campus with a range of menus

and offering

Traditional Plans

All students living on-campus are automatically assigned a meal plan.

Apartment Plans

All students living in Bettie Johnson Apartments, University Tower Apturents Iiving in Bettie Johnson Apartments, University Tower
Plan.

Commuter Plans

Living off-campus or commuting to campus brings a different set of needs and challenges to college life. Commuters and residents in the surrounding apartments are offered a select group of meal plans

Need help with your meal plan?

Figure A1. Meal Plan Website. "Meal Plans," (2019). 


\section{Traditional Plans}

All students living on-campus (undergraduate \& graduate) or undergraduate commuters classified as full-time attending at least 9 credit hours on the Belknap Campus, are automatically assigned a meal plan. All students living in Community Park, Kurz Hall, Louisville Hall, Miller Hall, Threlkeld Hall, and Unitas Tower are automatically enrolled in the All Access Plan. Students assigned to the All Access Plan can change to any of the Traditional Plans by completing the Meal Plan Change Form. Your Cardinal Card will be preloaded with your plan, applied to your tuition account, and will become active on move-in day.

Meal Plan changes are accepted online through the Cardinal Card Website. Your meal plan will reset to the standard plan each semester. Meal Plan changes must be made by the following dates:

- Fall 2019 Semester: August 29

- Spring 2020 Semester: January 16

Unused Meals expire at the end of each semester. Unused Flex Points will carry forward from fall to spring semester but will expire at the end of the academic year in the spring.

\section{Meal Swipes}

A meal swipe (or meal) can be used at multiple locations across campus, including the Ville Grill, our all-you-care-to-eat dining destination. All other dining locations accept a meal swipe for a full meal combo except for

convenience stores, and Starbucks. Meal swipes for locations other than the Ville Grill are limited to 7 per week.

\section{Flex Points}

Flex Points may be added at any time throughout the semester. There are two ways to add funds to your card:

1. Visit the Cardinal Card Office to add funds using cash, check, VISA, MasterCard, or Discover.

2. Online through the Cardinal Card Website using your ULink username and password using VISA, MasterCard, or Discover.

Bonus Flex Points:

Add $\$ 100$, get $10 \%$ Bonus. Add $\$ 200$, get $20 \%$ Bonus. Add $\$ 300$ (or more), get $25 \%$ Bonus.

Prices shown reflect the Fall 2019 and Spring 2020 meal plan prices, pending Board of Trustees approval. Students may change their meal plan during the current semester. The deadline to change your meal plan is August 29 for the Fall 2019 semester, and January 16 for the Spring 2020 semester. Your student account will be assessed the appropriate fees accordingly.

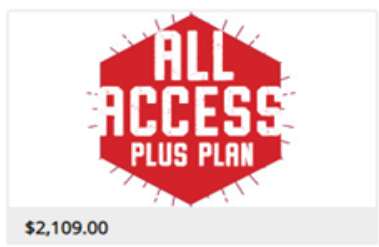

All Access Plus Plan

- Unlimited Meals

- \$325 Flex Points

- 10 guest meals

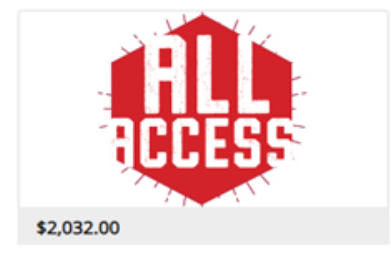

All Access Plan

- Unlimited Meals

- $\$ 175$ in Flex Points

\section{Meal Plans}

All Products

Traditional Plans

Apartment Plans

Commuter Plans

Figure A2. Traditional Plan Information. "Traditional Plans," (2019). 


\section{Apartment Plans}

All students living on-campus (undergraduate \& graduate) or undergraduate commuters classified as full-time attending at least 9 credit hours on the

Belknap Campus, are automatically assigned a meal plan. All students living

in Bettle Johnson Apartments, University Tower Apartments, and University

Pointe will automatically be enrolled in the 100 Plan. Students assigned to

the 100 Plan can change to any of the Apartment Plans or Traditional Plans

by completing the Meal Plan Change Form. Your Cardinal Card will be

preloaded with your plan, applied to your tuition account, and will become

active on move-in day.

Meal Plan changes are accepted online through the Cardinal Card Website.

Your meal plan will reset to the standard plan each semester. Meal Plan

changes must be made by the following dates:

- Fall 2019 Semester: August 29

- Spring 2020 Semester: January 16

Unused Meals expire at the end of each semester, Unused Flex Points will carry forward from fall to spring semester but will expire at the end of the academic year in the spring.

Meal Swipes

A meal swipe (or meal) can be used at multiple locations across campus, including the Ville Grill, our all-you-care-to-eat dining destination. All other dining locations accept a meal swipe for a full meal combo except for

convenience stores, and Starbucks. Meal swipes for locations other than the

Ville Grill are limited to 7 per week.

Flex Points

Flex Points may be added at any time throughout the semester. There are

two ways to add funds to your card:

1. Visit the Cardinal Card Office to add funds using cash, check, VISA MasterCard, or Discover.

2. Online through the Cardinal Card Website using your ULink username and password using VISA, MasterCard, or Discover.

Bonus Flex Points:

Add $\$ 100$, get $10 \%$ Bonus. Add $\$ 200$, get $20 \%$ Bonus. Add $\$ 300$ (or more). get $25 \%$ Bonus

Prices shown reflect the Fall 2019 and Spring 2020 meal plan prices, pending Board of Trustees approval. Students may change their meal plan during the current semester. The deadline to change your meal plan is August 29 for the Fall 2019 semester, and January 16 for the Spring 2020 semester.

Your student account will be assessed the appropriate fees accordingly.

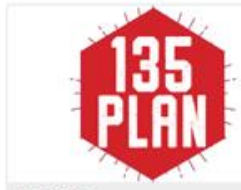

$\$ 1,694.00$

\section{Plan}

- 135 Meals per semester

- $\$ 410$ in Flex Points

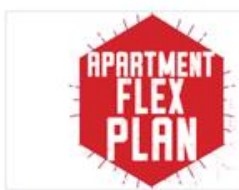

$\$ 1,083.00$

Apartment Flex Plan

- $\$ 1,083$ in Flex Points
Meal Plans

All Products

Traditional Plans

Apartment Plans

Commuter Plans

Figure A3. Apartment Plan Information. “Apartment Plans,” (2019). 


\section{Commuter Plans}

All students living on-campus (undergraduate \& graduate) or undergraduate commuters classified as full-time attending at least 9 credit hours on the Belknap Campus, are automatically assigned a meal plan. All students commuting from home or living in off-campus apartments Cardinal Towne, The Bellamy, The Clubhouse, The Nine, and Trifecta Apartments will automatically be enrolled in the Base Flex Plan.

Students assigned to the Base Flex Plan can change to any of the Commuter Plans, Apartment Plans, or Traditional Plans by completing the Meal Plan Change Form. Your Cardinal Card will be pre-loaded with your plan, applied to your tuition account, and will become active on move-in day.

Meal Plan changes are accepted online through the Cardinal Card Website. Your meal plan will reset to the standard plan each semester. Meal Plan changes must be made by the following dates:

- Fall 2019 Semester: August 29

- Spring 2020 Semester: January 16

Unused Meals expire at the end of each semester. Unused Flex Points will carry forward from fall to spring semester but will expire at the end of the academic year in the spring.

\section{Meal Swipes}

A meal swipe (or meal) can be used at multiple locations across campus, including the Ville Grill, our all-you-care-to-eat dining destination. All other dining locations accept a meal swipe for a full meal combo except for convenience stores, and Starbucks. Meal swipes for locations other than the Ville Grill are limited to 7 per week.

Flex Points

Flex Points may be added at any time throughout the semester. There are two ways to add funds to your card:

1. Visit the Cardinal Card Office to add funds using cash, check, VISA,

MasterCard, or Discover.

2. Online through the Cardinal Card Website using your ULink username

and password using VISA, MasterCard, or Discover.

\section{Bonus Flex Points:}

Add $\$ 100$, get $10 \%$ Bonus. Add $\$ 200$, get $20 \%$ Bonus. Add $\$ 300$ (or more) get $25 \%$ Bonus.

Prices shown reflect the Fall 2019 and Spring 2020 meal plan prices, pending Board of Trustees approval. Students may change their meal plan during the current semester. The deadline to change your meal plan is August 29 for the Fall 2019 semester, and January 16 for the Spring 2020 semester. Your student account will be assessed the appropriate fees accordingly.

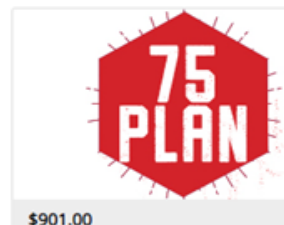

$\$ 901.00$

75 Plan

- 75 Meals per semester

- $\$ 240$ in Flex Points

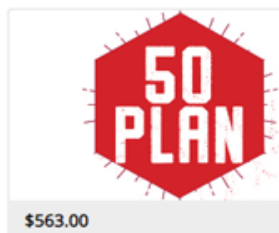

50 Plan

- 50 meals per semester

- $\$ 100$ in Flex Points
Meal Plans

All Products

Traditional Plans

Apartment Plans

Commuter Plans

Figure A4. Commuter Plan Information. "Commuter Plans,” (2019). 
APPENDIX C

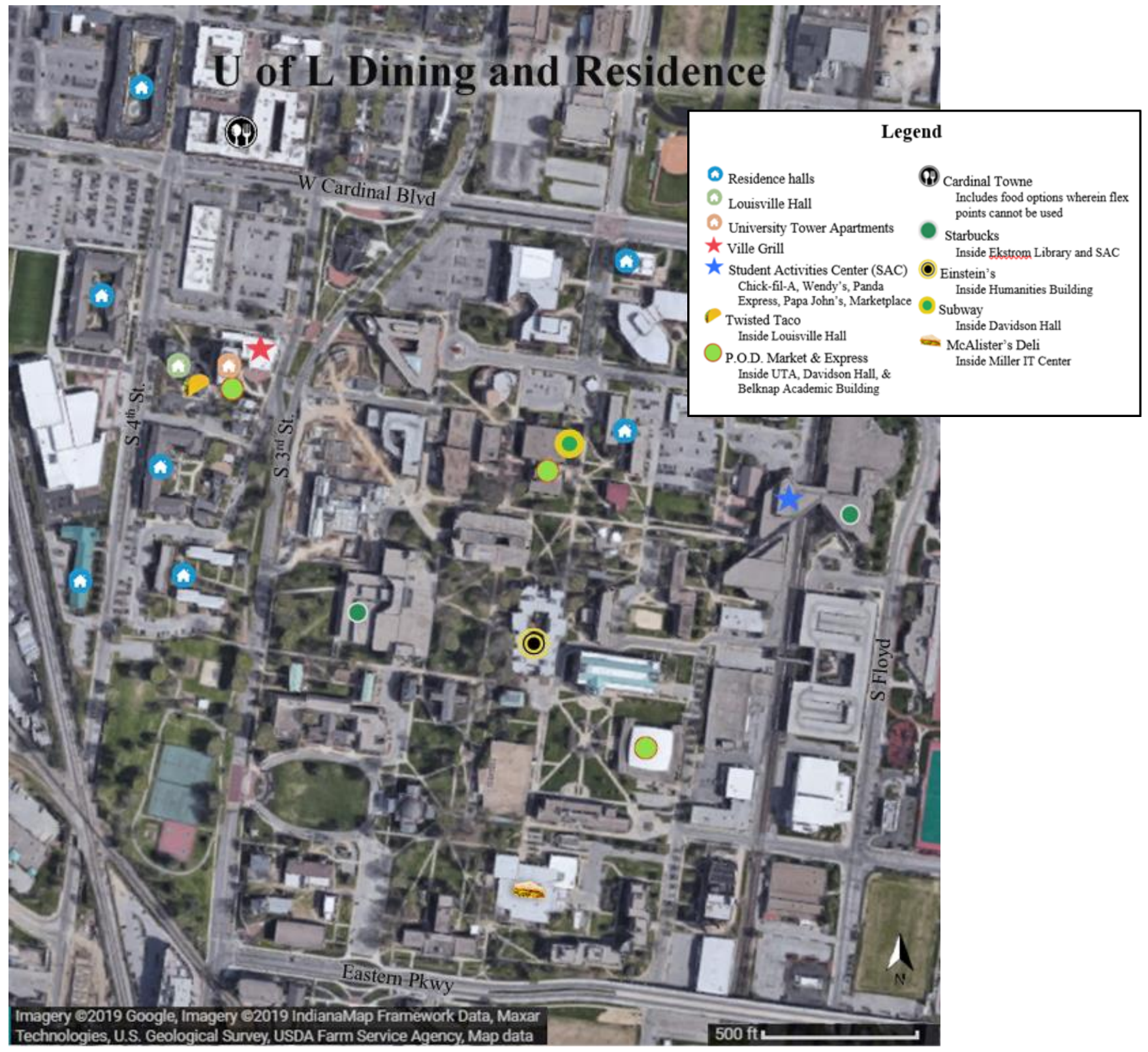

Figure A5. Campus Map for Dining and Residence Hall Proximity. 


\section{APPENDIX D}

\section{Ville Grill Images}
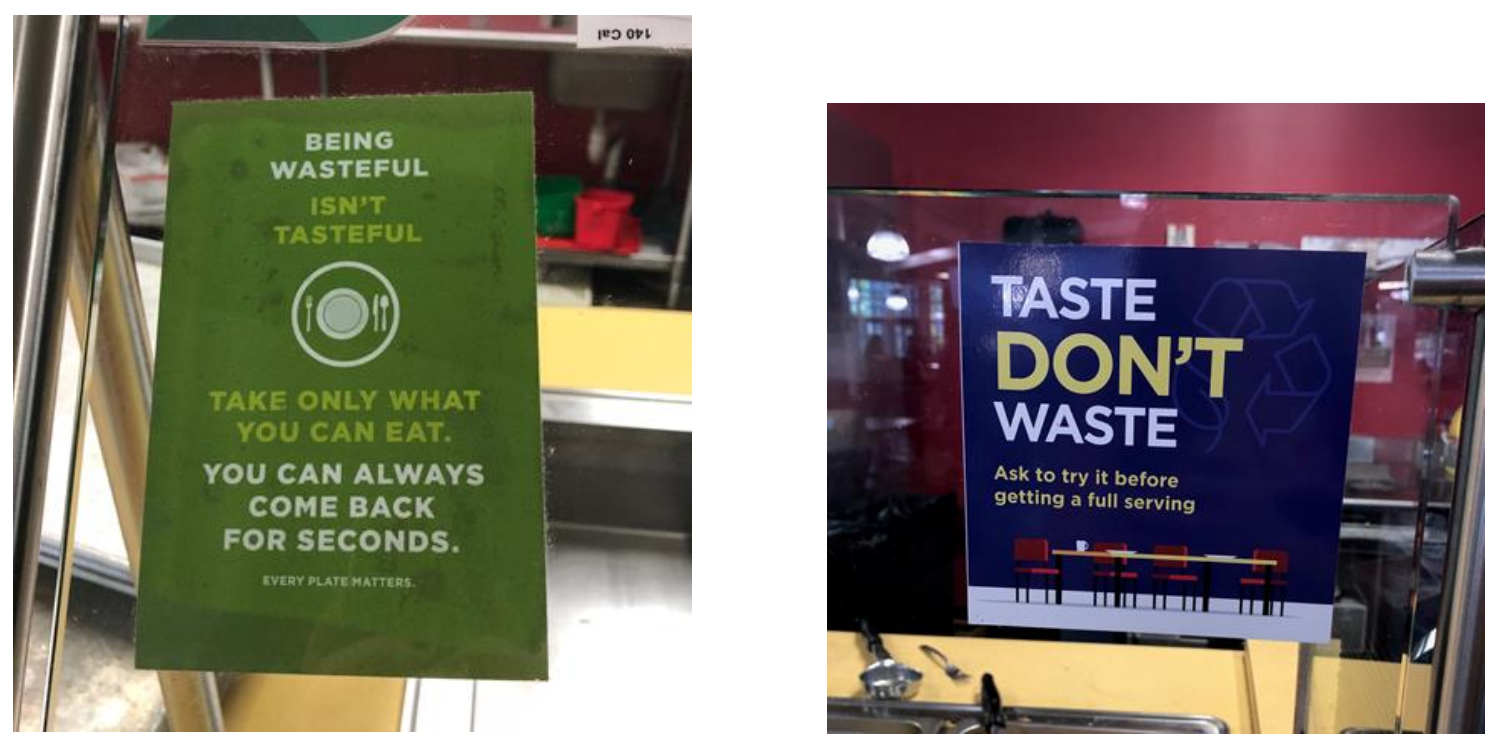

Figure A6. Former Sign about Tasting Dishes. Figure A7. New Taste Don’t Waste Sign
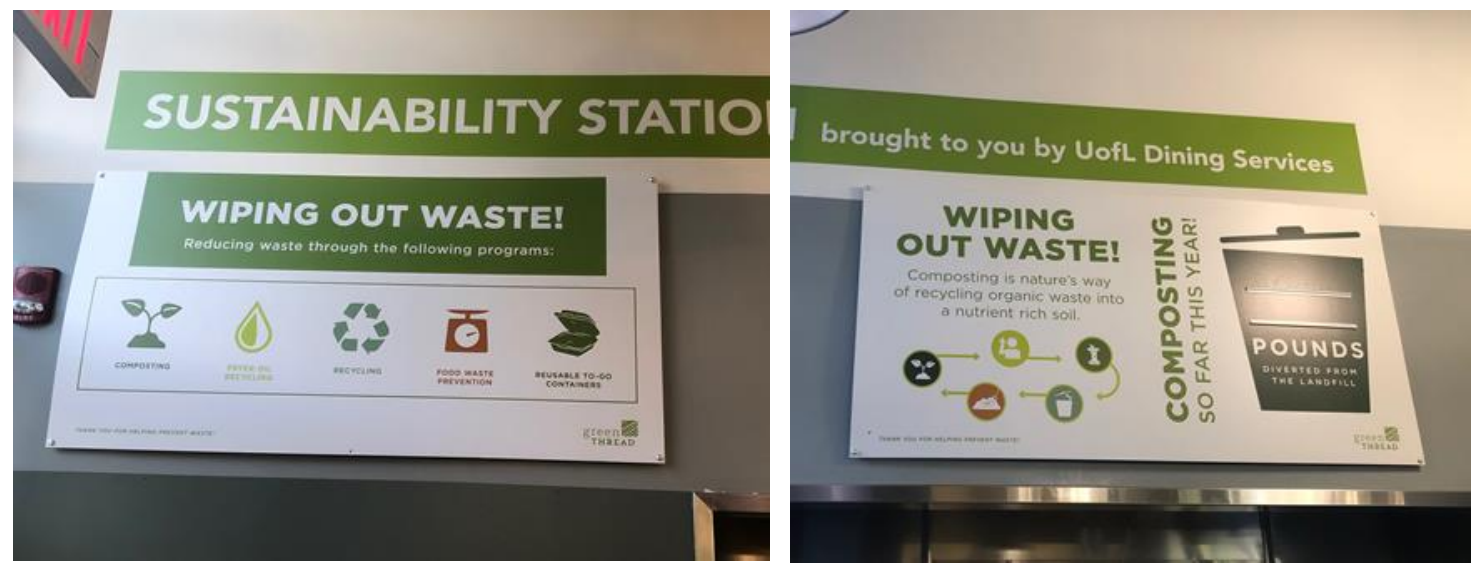

Figure A8. Ville Grill Compost Signs. Note: The number of pounds is in the process of being updated. 


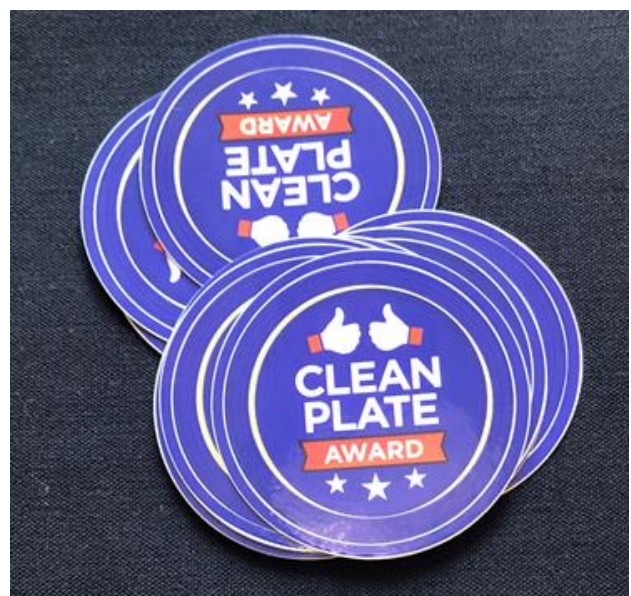

Figure A9. Clean Plate Award Sticker.
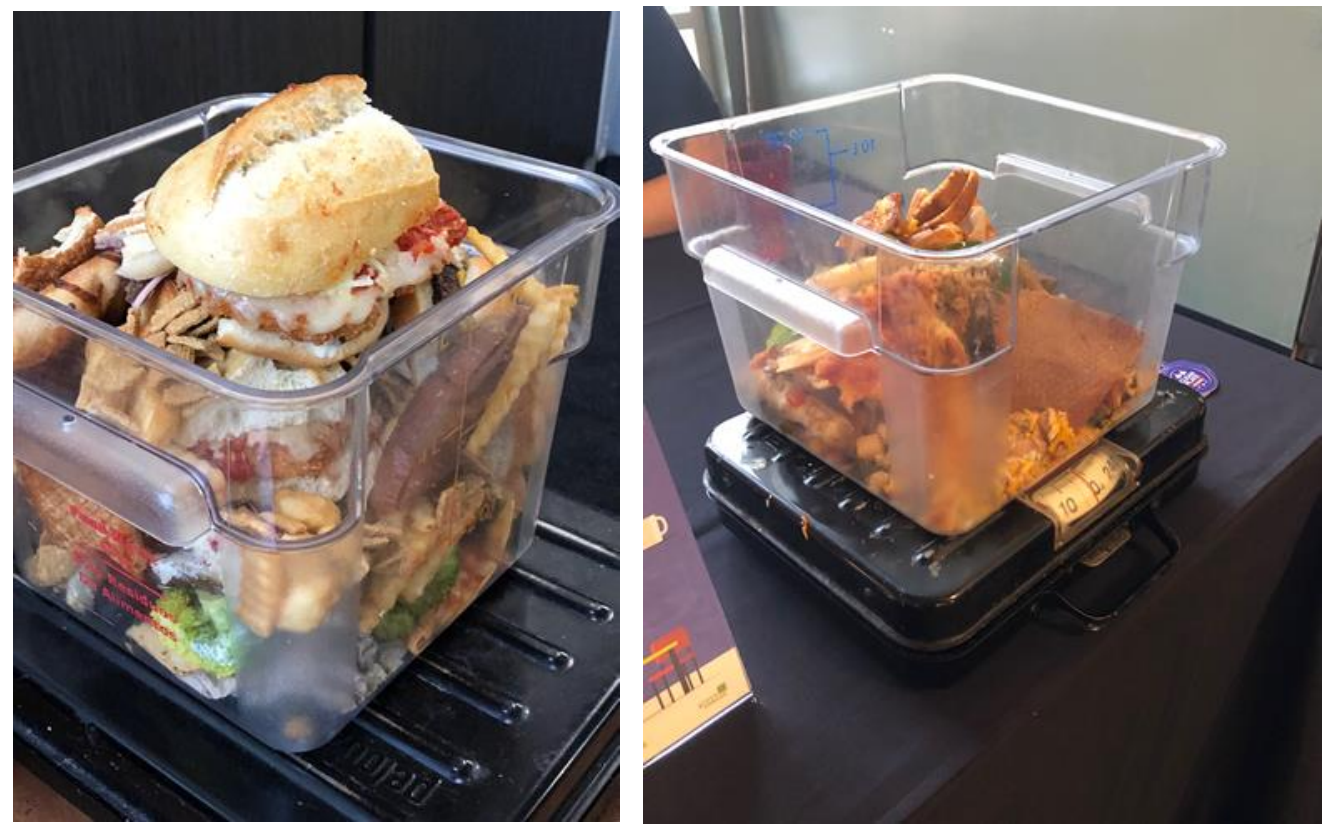

Figure A10. Weigh the Waste Images. 


\section{CURRICULUM VITA}

NAME: $\quad$ Cassie Anne Parkins

ADDRESS: 1334 S. Third St., Apt 7

Louisville, KY 40208

EDUCATION

\& TRAINING: $\quad$ M.S., Interdisciplinary Studies: Sustainability University of Louisville

2017-2019

B.S., Business Administration

Christopher Newport University

2013-2017

AWARDS: Graduate Fellowship, University of Louisville

2017-2019

Dean's List, Christopher Newport University

2015-2017

LEADERSHIP EXPERIENCE:

Campus Activities Board, Christopher Newport University

Culture and Lecture Committee Chair

2016-2017

EXTRACURRICULAR ACTIVITIES:

Food Literacy Project

Volunteer, 70 hours

September - December 2018

Campus Activities Board, Christopher Newport University Culture and Lecture Committee Member

2014-2016

Study Abroad, Christopher Newport University

June 2016

PROFESSIONAL AFFILIATIONS:

American Planning Association 